\title{
DESARROLLO CULTURALY PRINCIPALES CARACTERISTICAS ARQUITECTÓNICAS EN LOS SITIOS PREHISPANICOS DEL DISTRITO DE SAN PEDRO DE LARCAY, PROVINCIA SUCRE, DEPARTAMENTO AYACUCHO
}

\author{
Rafael MallCo HuARCAYA \\ UNIVERSIDAD NACIONAL SAN LUIS GONZAGA DE ICA \\ arql.rafaelmallco@hotmail.com \\ LUIS ANGULO PAREDES \\ UNIVERSIDAD NACIONAL SAN LUIS GONZAGA DE ICA \\ luis.angulop@gmail.com
}

\section{RESUMEN}

El presente artículo es una síntesis del resultado de los trabajos de investigación realizados durante los años 2008 y 2009 en el área del distrito de San Pedro de Larcay, lo cual conllevó en la documentación de 29 sitios arqueológicos correspondientes a diversos periodos de ocupación cultural, que de alguna forma u otra, nos indica que el valle Chicha-Soras y sus principales tributarios constituyó un área muy importante donde se desarrollaron sociedades prehispánicas desde el Periodo Formativo hasta el Periodo Horizonte Tardío. En el transcurso de este tiempo, las sociedades que se asentaron en estas áreas tuvieron sus propias formas de organización y desarrollo, producción de cerámica, características arquitectónicas y diferentes formas de dominio y aprovechamiento geográfico, aspectos de por cierto que son propios y distintivos uno del otro y nos permitió identificar la filiación cultural de cada uno de los sitios arqueológicos.

Palabras Clave: San Pedro de Larcay, sitios arqueológicos, periodos de ocupación cultural, sociedades prehispánicas, organización y desarrollo, arquitectura y medio geográfico.

\section{Abstract}

This article is a synthesis of the results of research work carried out during the years 2008 and 2009 in the area of the district of San Pedro de Larcay, which provided the documentation about 29 
archaeological sites corresponding to different periods of cultural occupation, these works, indicate that the valley Chicha - Soras and its principal tributaries constituted a very important area where pre-Hispanic societies developed from the Formative Period until the Late Horizon Period. In the course of this time, societies that settled in these areas had their own forms of organization and development, production of pottery, architectural features and different forms of domain and use geographical, aspects of which by the way are own and distinctive from each other and allowed us to identify cultural of each one of the archaeological sites filiation.

Keywords: San Pedro de Larcay, archaeological sites, periods of cultural occupation, pre-Hispanic societies, organization and development, architecture and geographical environment.

\section{INTRODUCCIÓN}

En el distrito de San Pedro de Larcay se encuentran una serie de evidencias arqueológicas que pertenecen a diversos periodos de ocupación cultural, sin embargo, estos sitios arqueológicos al igual que otros de la región de Ayacucho, a pesar de su importancia no han merecido una especial atención para su investigación y revalorización cultural que permita una óptima documentación, por ello las evidencias expuestas en superficie cada vez más están sufriendo procesos de depredación y deterioro que son causados por parte de la población y agentes naturales, quienes de manera directa e indirecta contribuyen a su paulatina destrucción, motivo por el cual nos impulsa escribir el presente artículo, que de alguna forma u otra contribuirá en el conocimiento de las diversas características de los sitios y su importancia teniendo en cuenta la perspectiva arquitectónica y de planificación de cada uno de los asentamientos.

\section{Ubicación del Distrito de San Pedro de Larcay}

El distrito de San Pedro de Larcay se encuentra ubicado en la margen izquierda del río Chicha -Soras, provincia Sucre, departamento de Ayacucho, entre las coordenadas UTM 654018 E - 8433135 $\mathrm{N}$ y a una altura de 3,384 m.s.n.m.

\section{Medio Ambiente}

El área del distrito de San Pedro de Larcay forma parte de una región del territorio peruano conocido como los Andes, cuya configuración ha sido determinada por la cordillera de los andes que atraviesa todo el territorio de norte a sur, su abrupta topografía con valles profundos y vertientes escarpadas ha generado una variada ecología por la diversidad de nichos ecológicos que se encuentran en los diferentes pisos altitudinales. La topografía del área es accidentada, con formaciones de valles estrechos, conjunto de colinas, pequeñas quebradas, laderas, cumbres, abismos y formaciones de grandes pampas en las partes altas. Esta parte de la región andina tiene un relieve escarpado, pero la mano del hombre a lo largo del tiempo ha modificado el paisaje mediante la construcción de un conjunto de sistemas de terrazas y andenerías que están establecidas en las partes medias y altas del valle.

\section{ANTECEDENTES DE INVESTIGACIÓN}

El área del distrito de San Pedro de Larcay fue visitado por diversos estudiosos e investigadores, quienes en su afán de conocer el desarrollo cultural y social de la zona identificaron diversos sitios con evidencias de ocupación prehispánica, lo cual permite conocer las sociedades que se asentaron en 


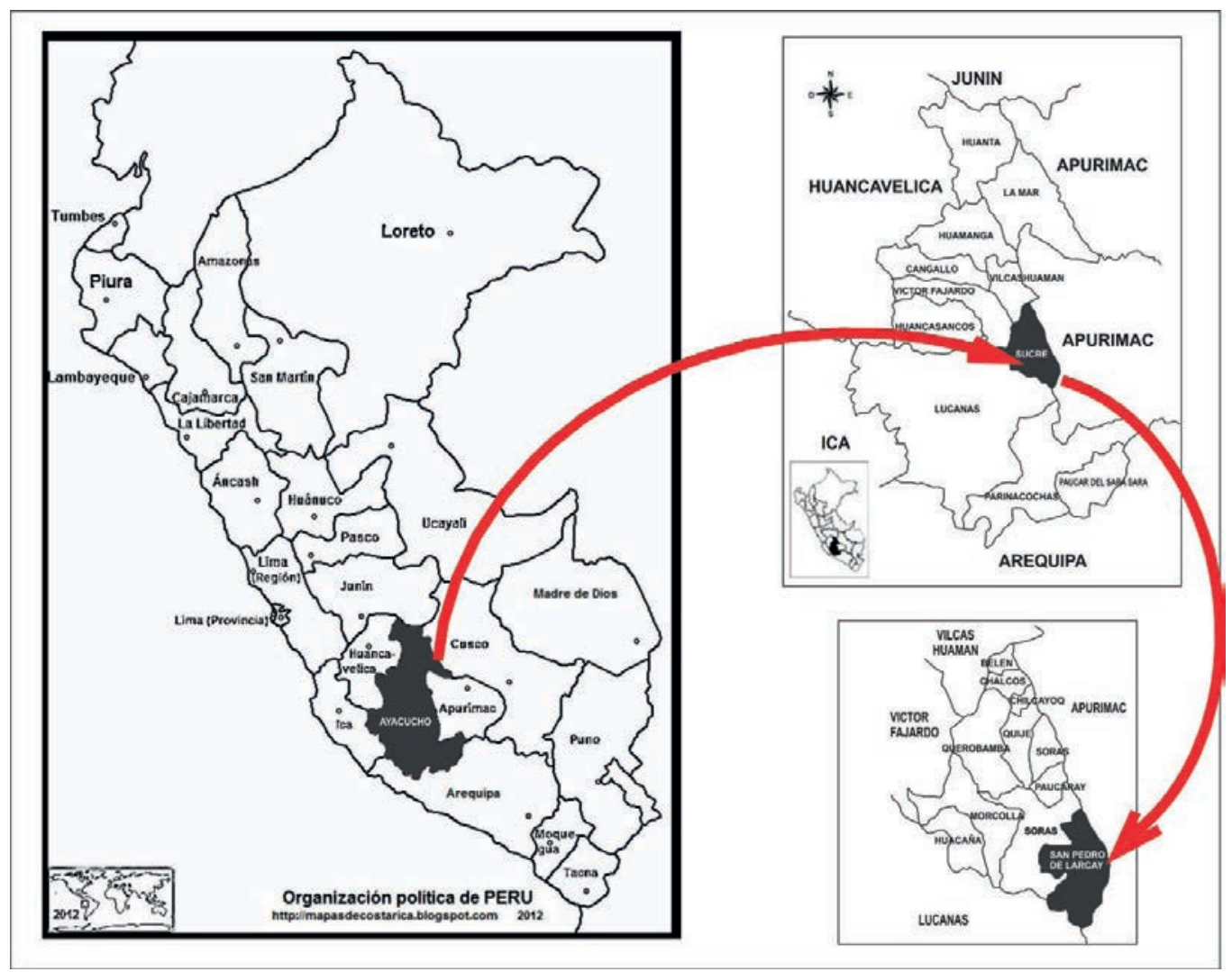

Figura № 1. Ubicación del distrito de San Pedro de Larcay

esta área mediante análisis y reconocimiento superficial de los materiales a través de comparaciones con evidencias de características similares identificadas en zonas aledañas y otras partes de la región. Los trabajos desarrollados en su mayor parte fueron a nivel de registro superficial que en cierta forma al no haber investigaciones con excavaciones contribuyen en el conocimiento de la historia de estos pueblos ubicados en la cuenca del río Chicha-Soras.

En 1551, el cronista Betanzos declara que los soras y lucanas junto con otros chancas provenientes de una región vecina tenían gran cantidad de soldados, posiblemente estos grupos fueron aliados y se enfrentaron contra los incas durante el momento de su expansión.

En 1978, por primera vez los ingleses Frank Meddens y Mónica Barnes exploran sistemáticamente los sitios arqueológicos de Qasapampa, Llaku, Mulluramachay en Larcay; Chicha Qasa y Chumado en Pampachiri, donde identifican nuevos sitios arqueológicos asociados con la alfarería Huari.

Posteriormente en 1980, los esposos Frank y Beverly Meddens, conjuntamente con Mónica Barnes realizan trabajos de excavación arqueológica en Chicha Qasa (Pampachiri) y Chiqnajota (Larcay), para confirmar su hipótesis planteada en 1978. Los resultados de esta investigación mostraron estratigrafía asociada con fragmentos de cerámica del estilo Huari, cerámica local (Soras) asociados a fragmentos de huesos de animales de la fauna de este periodo. 
En 1981, Mónica Barnes continuó explorando la cuenca del valle del río Chicha e identificó algunos sitios arqueológicos bastante importantes con cerámica Huari, además exploró el sector de Huayllaripa donde encontró evidencias arqueológicas prehispánicas de explotación de lavaderos de oro.

En 1982, los esposos Frank Meddens y Beverly Meddens interesados por conocer el tema del Horizonte Medio, continuaron con las excavaciones arqueológicas en Chiqnajota donde se llegó a identificar un callejón angosto techado con lajas de piedra que correspondería a la época 2B del Horizonte Medio. Por otro lado, los trabajos de esta temporada han sido bastante sorprendentes por el descubrimiento de ofrendas Huari y ofrendas Inca en estratigrafía Huari formado por pequeños objetos de cerámica.

En 1984, el antropólogo Héctor Espinoza procedente de esta zona es el primero en realizar exploraciones arqueológicas sistemáticas en toda el área del distrito de San Pedro de Larcay e identifica el mayor número de sitios arqueológicos de la zona, además Espinoza en el mismo año realiza trabajos de excavación en Wallpahuiri al interior de la Kallanka e identifica estratos de ceniza y un piso bien constituido que indica una larga utilización de este edificio, en sus excavaciones recuperó escaso material arqueológico principalmente de filiación Inca.

En 1990, Meddens realiza trabajos de excavación en el cementerio de Charanguchayuq o Kallpa y registra gran cantidad de tumbas colectivas e individuales que pertenecieron a posibles dignatarios de la cultura Huari, la fachada principal del cementerio había sido pintada de blanco y presentaban recintos de hasta tres niveles.

En 1999, Meddens amplía sus trabajos de investigación e interviene en Chiqnajota en la cual recupera gran cantidad de fragmentos de cerámica Huari del estilo Ocros, Viñaque, Huamanga y Negro Decorado, además los trabajos de prospección en esta temporada permitieron identificar nueve sitios más fechados al Horizonte Medio y un templo en forma de "D" en Yako.

En el año 2005, Ann Kendall como parte de sus trabajos en la ONG The Cusichaca Trust realiza excavaciones de una trinchera que le permitió conocer la profundidad del reservorio, así como identificar el punto de desfogue del agua. Durante sus trabajos recuperó gran cantidad de cerámica Huari, lo cual indicaría que estos reservorios o qochas fueron utilizados desde el Horizonte Medio hasta la época Inca. Años más tarde como parte de sus trabajos de recuperación de sistemas agrícolas tradicionales, los reservorios, los canales y andenes prehispánicos de Layme fueron recuperados y actualmente son utilizados como áreas agrícolas para la siembra de maíz y papa.

En los años 2009, 2010 y 2013 los arqueólogos Rafael Mallco y Luis Angulo realizan trabajos de reconocimiento sistemático del área y registran 29 sitios con arquitectura que les permitió conocer la tipología arquitectónica de los sitios y de esta manera a través del análisis de la interrelación de los sitios arqueológicos con su paisaje establecer los patrones de asentamiento. Los trabajos efectuados en la margen izquierda del rio Chicha y sus principales tributarios como son las subcuencas del río Pachachaka y Huancani aportan muchísimas informaciones, puesto que también permitieron conocer datos etnoarqueológicos y antropológicos.

En el año 2015, las arqueólogas Stephanie del Castillo y Scotti Norman del Proyecto Arqueológico Taki Onqoy realizan excavaciones arqueológicas en diversos sectores de Iglesiachayuq con la finalidad de identificar el impacto del movimiento mesiánico durante la época Inca, los trabajos permitieron recuperar importantes informaciones arqueológicas que la investigadora posteriormente dará a conocer a la comunidad científica. 


\section{Principales Sitios Arqueológicos}

Los principales sitios arqueológicos identificados en el área del distrito de San Pedro de Larcay que permitieron conocer el proceso de ocupación y el análisis de los patrones de asentamiento son:

Tabla $N^{\circ}$ 1. Sitios arqueológicos identificados en el área de distrito de San Pedro de Larcay

\begin{tabular}{|c|c|c|c|c|}
\hline \multirow{2}{*}{ № } & \multirow{2}{*}{ SITIOS ARQUEOLÓGICOS } & \multirow{2}{*}{ NOMENCLATURA } & \multicolumn{2}{|c|}{ UTM } \\
\hline & & & $\mathrm{E}$ & $\mathrm{N}$ \\
\hline 01 & Chiqnajota & SCPH(Chi) -01-SPL & 0658383 & 8427070 \\
\hline 02 & Obrajería & SCPH(Obr) -02-SPL & 0658207 & 8427316 \\
\hline 03 & Puka Orqo & SCPH(Puk) -03-SPL & 0658566 & 8427330 \\
\hline 04 & Raqayniyuq & SCPH(Raq) -04-SPL & 0658074 & 8427532 \\
\hline 05 & Onqa & SCPH(Onq) -05-SPL & 0657913 & 8427396 \\
\hline 06 & Pachachaka & $\mathrm{SCPH}(\mathrm{Pac})-06-\mathrm{SPL}$ & 0658187 & 8426534 \\
\hline 07 & Wallpawiri & SCPH(Wal) -07-SPL & 0657210 & 8428414 \\
\hline 08 & Iglesiachayoq & SCPH(Igl)-08-SPL & 0657014 & 8428322 \\
\hline 09 & Sikaupukro & SCPH(Sik)-09-SPL & 0657261 & 8430616 \\
\hline 10 & Chaupiranra & SCPH(Cha)-10-SPL & 0656894 & 8428164 \\
\hline 11 & Qotawañe & SCPH(Qot)-11-SPL & 0657022 & 8427988 \\
\hline 12 & Tayapukro & SCPH(Tay)-12-SPL & 0656685 & 8429668 \\
\hline 13 & Kallpa & SCPH(Kal)-13-SPL & 0655690 & 8430616 \\
\hline 14 & Yako & SCPH(Yak)-14-SPL & 0655394 & 8431646 \\
\hline 15 & Qasamarca & SCPH(Qas)-15-SPL & 0655285 & 8432566 \\
\hline 16 & Turkuymalla & SCPH(Tur)-16-SPL & 0654315 & 8430650 \\
\hline 17 & Soqía & SCPH(Soq)-17-SPL & 0653948 & 8432330 \\
\hline 18 & Sillacha & SCPH(Sil)-18-SPL & 0654174 & 8434098 \\
\hline 19 & Potongo & SCPH(Pot)-19-SPL & 0653770 & 8434252 \\
\hline 20 & Sullumachay & SCPH(Sul)-20-SPL & 0653588 & 8435250 \\
\hline 21 & Karpani & SCPH(Kar)-21-SPL & 0653157 & 8435634 \\
\hline 22 & Layme Qocha & SCPH(Lay)-22-SPL & 0653100 & 8435740 \\
\hline 23 & Pulluhuay & SCPH(Pul)-23-SPL & 0653074 & 8435820 \\
\hline 24 & Marcalo & SCPH(Mar)-24-SPL & 0652420 & 8435350 \\
\hline 25 & Kullkuncha & SCPH(Kul)-25-SPL & 0638696 & 8428010 \\
\hline 26 & Kusmairo & SCPH(Kus)-26-SPL & 0642527 & 8426184 \\
\hline 27 & Doce corrales & SCPH(Doc)-27-SPL & 0645863 & 8412594 \\
\hline 28 & Alala & SCPH(Ala)-28-SPL & 0643696 & 8410076 \\
\hline 29 & Tororayoq & SCPH(Tor)-29-SPL & 0654755 & 8433754 \\
\hline
\end{tabular}




\section{Proceso de Ocupación Cultural}

Así como la región de Ayacucho presenta una secuencia de ocupación cultural que comprende desde el periodo lítico hasta la época Inca; en el área del distrito de San Pedro de Larcay se reporta información arqueológica que indica un proceso de ocupación cultural que comprende desde el periodo inicial hasta la época Inca en el Horizonte Tardío, en el transcurso de ese tiempo los grupos humanos desarrollaron una serie actividades, pero a medida que se desarrollaban fueron adquiriendo nuevas formas de vida y se diferenciaban unos de los otros, pues cada cual poseía sus propias características, entonces, es a partir de esas diferencias que nosotros podemos clasificar las poblaciones y los tipos de patrones de asentamientos, así mismo conocer el desarrollo cultural que alcanzaron durante cada periodo de desarrollo.

En el Periodo Inicial ocurren una serie de cambios, se producen el retiro de los deshielos, el clima alcanza temperaturas favorables y crea ambientes propicios para el desarrollo del hombre, los animales y las plantas; la abundancia de animales para la caza y de frutos, semillas y otros vegetales para la recolección dio, como resultado que la población aumentase y las bandas se hiciesen numerosos al igual que en otras partes de la región. La población al incrementarse ocupó amplios territorios, pobló la mayoría de las cuevas y abrigos rocosos, como también construyó campamentos al aire libre donde establecían sus viviendas y este tipo de evidencias se han encontrado cerca de Yanama y Negro Mayo, ambos sitios pertenecen a la jurisdicción de Chipao. En el área de la cuenca del río Chicha -Soras se identificó un sitio A-23 correspondiente al Periodo Inicial (Meddens,1999),, en la cual se encontró concentración de material lítico y cerámica del estilo Muyo Moqo, esta evidencia demostraría que el sitio fue utilizado para manufacturar herramientas líticas.

En cambio las evidencias que corresponden al Formativo o Periodo Horizonte Temprano se han reportado en ambas márgenes del río Chicha, en el sitio denominado Santa Rosa o Lawa Lawa, Autama y Chicha (Meddens, 1999). La cerámica descubierta en Autama fue hallado en asociación con entierros y con cuchillos unifaciales de basalto, la cerámica identificada es de color rojo llana ennegrecida por el uso doméstico. La cerámica monocroma de Chicha es bruñida pulida con facturas en la cara externa de buena calidad, la cara interna es trapeada y escobillada, mientras que la cerámica de Santa Rosa sería de color rojo inciso. Según los reportes de Héctor Espinoza y Frank Meddens, la cerámica encontrada en estos sitios tiene influencia Chavín y Paracas, de lo conocido se puede afirmar de manera tentativa que la región de Ayacucho durante el periodo que comentamos fue una zona de vida rural y aldeana.

En el Periodo Intermedio Temprano es que recién empiezan a llegar los primeros grupos debidamente organizados, pero en este caso, los primeros grupos que llegaron al área de Larcay fueron gente que vinieron de la parte norte de la región de Ayacucho y estuvieron representados por los huarpas, las primeras evidencias de fragmentos de cerámica Huarpa fueron identificados en el sitio de Tororayoq- Huahuerqa dentro de las áreas de cultivo, los fragmentos presentan diseños de color rojo o negro sobre un fondo de color crema o blanco. En Tororayoq no solamente se encuentran fragmentos de cerámica Huarpa, sino también recintos habitacionales de formas circulares que en su mayor parte están devastados por la agricultura.

En los andenes de Huahuerqa se puede observar fragmentos de cerámica Huarpa asociados a puntas de obsidiana, algunos cuchillos y a fragmentos de cerámica correspondiente al Horizonte Medio. La presencia Huarpa en el valle Chicha- Soras, sería una de las primeras evidencias concretas que indiquen la ocupación del área a partir del Intermedio Temprano. La primera sociedad que se desarrolló en este sitio, posiblemente estuvo organizado en aldeas menores con tres o cuatro viviendas y tenían 
como actividad principal la agricultura basada en la siembra del maíz, mientras que la práctica de la ganadería habría tomado fuerza años más tarde.

En el Horizonte Medio, después de la presencia Huarpa en el valle Chicha- Soras, empiezan a llegar grupos humanos procedentes de Ayacucho hacia el año 600 d.C. aproximadamente, sometiendo a su dominio a pequeños grupos de pastores y agricultores que ocupaban esta zona. Según nuestro criterio y por las evidencias encontradas, Sillacha sería uno de los primeros sitios con ocupación Huari en nuestra zona de estudio, seguido de Yako y Chiqnajota. Nuestra hipótesis de la presencia Huari en el área se basa en la identificación de cerámica temprana correspondiente al Horizonte Medio, los fragmentos son muy finos a comparación de los demás sitios. No obstante, presencia de arquitectura ortogonal identificada por los pobladores, en el momento que construían una vivienda, nos conllevó inferir que este sitio, posiblemente sea uno de los primeros asentamientos ocupados por la cultura Huari. A simple vista, el sitio no presenta evidencia de arquitectura, sin embargo con una observación detallada se puede identificar algunos alineamientos de muros que se encuentran bajo la superficie, los cuales corresponderían a la época 1B del Horizonte Medio.

Yako sería el segundo sitio que representa la época temprana del Horizonte Medio en el valle Chicha-Soras, puesto que ahí se identificaron material cerámico que pertenece a las primeras épocas del Horizonte Medio. Creemos que los primeros grupos Huari que llegaron a la cuenca del río Chicha, en un primer momento se asentaron en Sillacha, posteriormente los mismos grupos en busca de nuevos territorios avanzan hacia el Sur, se asientan en Yako y Chiqnajota, donde tuvieron un largo periodo de desarrollo cultural, es posible que estos dos últimos sitios fueron los centros de mayor importancia en la cuenca del valle Chicha - Soras al igual que su similar de Jicamoqo que se desarrolló en la cuenca del río Sondondo (Schreiber, 2000).

Yako es un sitio representativo de varios periodos y cubre las épocas 1 y 2 del Horizonte Medio.

La cerámica más temprana recobrada en la excavación de Meddens pertenece al Horizonte Medio y sugiere las influencias de Huarpa y Ocros.

Durante los trabajos de prospección en Yako, en el primer sector se identificó un posible templo en "D", que está asociado a estructuras de tipo ortogonal en su parte posterior, además uno de los recintos que se encuentra cerca, presenta pequeños nichos pintado de color blanco y la parte recta del edificio se orienta en dirección este. También Meddens (1999), identificó un posible templo en "D" con sus respectivos nichos en el interior de sus paredes, el cual estaría en la parte baja del sitio, específicamente en el tercer sector denominado Qatun Yako. Estas evidencias arquitectónicas, muestran la ocupación del sitio por un largo periodo, en ese lapso de tiempo se desarrollaron una serie de actividades como la agricultura, la ganadería y el comercio. El desarrollo de la agricultura conllevó a que los habitantes construyeran un sistema de andenerías y practicaran una agricultura de secano, de la misma forma, para transportar los productos de las chacras se tenían que construir pequeños caminos.

El abandono de Yako por los huaris se dio posiblemente a finales de la época 2 del Horizonte Medio, esta situación se repite en otros sitios Huari del valle de Ayacucho, sin embargo, después de la ocupación Huari, muchos sitios del valle Chicha fueron reocupados durante el Periodo Intermedio Tardío y en el caso de Chiqnajota, sería uno de los únicos sitios donde se pueda encontrar la más completa información sobre la secuencia del proceso ocupacional que corresponde al valle Chicha- Soras.

Kallpa es un cementerio que está directamente asociado al sitio de Yako y se encuentra en la parte alta del sector Marcatocsaqocha, las evidencias constructivas del sitio, nos indican su uso desde las 
primeras épocas del Horizonte Medio, hasta el Intermedio Tardío y presenta un constante proceso de remodelación. El sitio está interconectado por un camino que pasa cerca del cauce de agua que discurre a Qatun Yako, se extiende desde la parte baja y en la parte media se asocia a una pequeña plazoleta acondicionada sobre un montículo natural, espacio que posiblemente sirvió como descanso durante el traslado de los muertos.

Chiqnajota, también es otro de los sitios que presenta las más clara evidencia de ocupación Huari en nuestra zona de estudio, los recintos que lo conforman son de tipo ortogonal y están interconectados por pequeños corredores, los muros presentan voladizos, aplicaciones de estuco y pequeños nichos. En el montículo superior de Chiqnajota en un huaqueo dentro de un recinto circular se observó restos de arquitectura Huari a una profundidad aproximada de 1.50 metros desde la superficie.

Para Meddens (1999), el sitio Arqueológico de Chiqnajota ha sido ocupado en el Horizonte Medio, inclusive hasta el periodo Inca. El sitio fue planificado alrededor de tres plazas hundidas y dos colinas. Una de las construcciones que excavó consistió de un corredor estrecho dividido en pequeñas unidades celulares, construido en la Época 2 del Horizonte Medio. Aproximadamente, al final de la época 2, es decir cuando Wari alcanzó su máximo apogeo en su organización económica, política y expansión cultural, ocurrió el colapso y abandono de la capital del estado. Este acontecimiento histórico habría repercutido en todo el dominio territorial Wari, al igual que los valles de San Miguel, Chumbao, Chicha-Soras, Mantaro, Carahuarazo y posiblemente la cuenca del Pampas y Caracha sufrieron consecuencias semejantes y al parecer fueron simplemente abandonados y traslados a lugares más apropiados (Vivanco, 1998: 177). Para nosotros la cultura Huari decae como consecuencia de un cambio climático y una crisis política originada por sus propios gobernantes, que al no tener suficiente capacidad de administrar el vasto territorio y por las constantes luchas internas entre los grupos de poder, permitieron la fragmentación de la clase gobernante, entonces los grupos divididos empiezan con la lucha interna y la poca aceptación de los gobernantes en los centros provinciales incrementa el caos social, en general la decadencia de los huaris, no sólo estaría acompañado por la crisis social, sino también por una alteración y crisis climática donde el fenómeno del niño fue muy devastador y se produjo muchos años de sequía que conllevaron a un desequilibrio social y económico.

Durante el Periodo Intermedio Tardío, después de la decadencia Huari, los grupos locales que se asentaron en la cuenca del río Chicha- Soras empiezan a desarrollarse independientemente al igual que otros de zonas aledañas y es en este lapso de tiempo que surgen los grupos étnicos denominados Soras, Chichas, Chalcos, Antamarkas y Rucanas; sin embargo los Chichas y los Soras fueron los grupos étnicos dominantes en la cuenca del río Chicha- Soras y tuvieron como centros de ocupación principal a Chiqnajota y Taqrampa, posteriormente los Chichas al extenderse se asientan en un poblado fortificado que se encuentra en la cima y en la ladera noroeste del cerro acuchillado de Qasamarka. Los Chichas son los grupos étnicos locales que dominan el valle durante la primera época del Intermedio Tardío, se extienden hasta las punas y ocupan los actuales territorios de Pampachiri, Larcay, Soras, Paucaray, Paico y Sihue.

Los Chichas, aun temían una posible invasión por parte de grupos foráneos, por ello, para dar mayor seguridad y resguardo de sus poblaciones deciden ocupar las partes altas y estratégicas de los cerros, puesto que ante un eventual ataque ellos fácilmente podían responder al enemigo, en ese afán no les importó resaltar su arquitectura ni religión, más bien se preocupaban por sobrevivir y no ser sometidos, por eso construyeron sus viviendas aglutinadamente sin orden alguno en las partes altas de los cerros. Obrajería y Qasamarca son los principales centros de defensa, aunque el primero es más antiguo que surge desde la época Huari. 
A parte de Chiqnajota, los Chichas tuvieron otros poblados menores bajo su dominio y se encuentran en Chicha Qasa, Puka Orqo, Qasamarca, Yako, Onqa, Raqayniyuq, Karpani y Marcalo. Las evidencias más resaltantes de la ocupación Chicha en el valle del mismo nombre se encuentran en su cerámica, este presenta engobe de color rojo con acabado no muy fino, este tipo de cerámica se encuentra en todos los sitios de ocupación tardía, incluso en lugares de ocupación Inca.

Estas evidencias nos dan entender que los Chichas ocuparon un amplio territorio y no sólo comprende la cuenca del río Chicha, sino también las áreas de los actuales territorios de Soras, Pampachiri y Pomacocha. Posteriormente a mediados del Intermedio Tardío, los Soras correspondientes a un grupo étnico vecino empieza adquirir importancia en el valle y son los que posteriormente dominarán el área previa unificación con los Chichas. Posteriormente el territorio ocupado por los Soras es ocupado por los Chancas con un sistema político más sólido y con una estrategia militar expansionista, lo cual conllevó a formar la posterior confederación Chanca.

Con respecto a ello (Meddens y Vivanco , 2002), señalan que los soras fueron uno de los grupos que pueden a veces haber estado aliados a los chankas. Su ideología sirve para ilustrar el hecho que las estructuras de los sistemas de creencias en las áreas de Huancavelica, Apurímac y Ayacucho durante el Intermedio Tardío fue muy similar.

Los Soras después de la invasión Chanca igual fueron Importantes, es por ello que los Incas sufrieron para derrotarlos. La lengua que hablan los chichas y los soras antes de la conquista Inca era el Aymara. En tiempos de la colonia la lengua predominante era el quechua, siguiendo la tradición impuesta por los incas. Sin embargo, antiguamente los Soras hablaban diversas lenguas que posteriormente fueron llamados genéricamente huahuasimi. Es posible que los soras derrotados por $\mathrm{Pa}-$ chacutec, fueron obligados a construir los aposentos y edificios públicos de Vilcashuamán, bajo la dirección de maestros traídos del Cuzco. Una vez que fueron incorporados los Soras al creciente Tahuantinsuyo, se construyeron varios asentamientos Incas, sobre los poblados nativos en Soras y en Pampachiri (Chiqnajota), y a los habitantes se les impuso como obligación que sirviesen al Inga de correos y traerle en unas andas y entre trabajo y ocupación pagaban el tributo. En realidad los soras fue un grupo étnico que estaba integrado a los chancas, sin embargo tenían ciertas diferencias con ellos tal como nos informa la relación de los soras que escribió Monzón en 1586. Después de haberle ganado la guerra a los soras, Pachacutec se dirige a territorio de los rucanas y auqimarcas, sometiéndoles bajo su dominio después de una tenaz resistencia; posteriormente incorporó a los qatun rucanas y laramatis; en seguida Pachacutec se dirigió a Pucara donde se habían refugiado los pobladores de la región desde los soras hasta ambas márgenes del río Pampas, regresando finalmente a Vilcashuamán.

Una de las principales cuencas de la provincia de Sucre está conformada por un gran número de sitios ocupados durante el Intermedio Tardío, por ello la cuenca de río Chicha-Soras, que viene a ser un límite natural entre los departamentos de Apurimac y Ayacucho, formó parte del área de desarrollo de los chancas, pero antes estuvo ocupada por grupos locales como los chichas y los soras, años más tarde ante la invasión incaica, estos grupos al igual que otros en la región de Ayacucho formaron alianzas para poder defenderse y desde entonces adquiere la denominación de Confederación Chanca, que no es más que otra cosa que una denominación dada a la agrupación de grupos étnicos locales que se desarrollaron en la Sierra Centro Sur del Perú. Cuando llegaron los primeros españoles y cronistas al sitio, solo identificaron a los soras como un grupo que había permanecido después de los enfrentamientos bélicos, además cuando los incas conquistaron este territorio se asentaron en el actual distrito de Soras y construyeron grandes palacios, ante tal evidencia los viajeros no tuvieron otra opción que llamarlos soras, por ello, hoy en día las fuentes bibliográficas solo mencionan a los soras, mas no a los chichas, sin embargo, el material arqueológico identificado en el área, señala lo 
contrario, los sitios más grandes y numerosos se encuentran en Chicha y no en Soras, es posible que los incas tuvieron peligrosidad de ellos y los reportaron hacia territorios amazónicos y zona de Bolivia, por ello, en la actualidad existen dos provincias en el altiplano boliviano y se denominan los Nor Chichas y los Sud Chichas, en ambas provincias no se habla el aymara, más bien se habla el idioma Quechua igual que en Ayacucho.

El Periodo Horizonte Tardío en el valle Chicha - Soras se caracteriza por el dominio de los incas, que son un grupo proveniente del Cuzco que en su afán expansionista, después de haber derrotado a los chancas en la batalla de Ichupampa, somete a los grupos étnicos locales y así domina hasta el final. Una vez que Cusi Yupanqui, posteriormente denominado Pachacutec, venció al ejercito Chanca, no se aventuró a grandes campañas de expansión, porque todavía no era lo suficientemente fuerte. Dominado los alrededores del Cuzco, Pachacutec, que a partir de su coronación y matrimonio había adoptado un nuevo nombre trató de anexar de acuerdo a un plan expansivo los territorios vecinos a Andahuaylas, como los Soras, Vilcas, Rucanas, Pucaray y que habían sido centros Chancas o que por lo menos los habían apoyado durante el ataque al cusco. (Pérez; Purizaga y León; 2007: 151).

Sin embargo, antes de llegar a la cuenca del río Chicha, Pachacutec y su ejército cuando salieron de Andahuaylas hacia Soras envió a sus emisarios para que les solicitasen que no tomen armas contra él, más bien prometía darles beneficios, por ello construyeron el canal de Huayllacha que va desde la bocatoma que se encuentra en el río Huancani hasta Soras. También se sabe que llegar a la cuenca del río Chicha no era fácil, mucho menos conquistar a los grupos étnicos locales, es por tal motivo que los incas tuvieron aprieto y pasaron una serie de penumbras. En su campaña de expansión, Pachacutec cruzó el río Apurímac por el puente Cunyac, llegando a los aposentos de Cura Huasi, donde tuvo un buen recibimiento. En este lugar tuvo un encuentro amigable y pacífico con uno de los jefes chancas llamado Túpac Uasco. Siguiendo su recorrido tuvo un enfrentamiento contra los naturales de Curamba a quienes venció en una batalla y después de hacer el escarmiento necesario y disponer lo conveniente, como la construcción de asentamiento Inca de Curamba, anexó e incorporó el lugar a la administración incaica, Pachacutec continuó hacia Andahuaylas, siendo bien recibido en este lugar donde pasó algunos días descansando y quizá planificando la construcción Inca inicial de Sondor, alrededor de ocupaciones Chancas del santuario de Muyu Muyu y de otros asentamientos antiguos.

Por esta razón antes de llegar a la cuenca del río Chicha-Soras, los incas y sus huestes pasaron por Curamba y Sondor, donde construyeron un monumento que representaba su dominio en Apurímac. Pachacutec, después de haber pernoctado algunos días en Sondor se dirige al valle Chicha- Soras y se enfrenta con los grupos locales, y ante la superioridad, estos últimos fueron sometidos. Aprovechando el sometimiento, los Incas inmediatamente ocupan los actuales territorios de Larcay y Soras, construyen grandes edificios, se asientan en Iglesiachayuq, Wallpawiri, Chiqnajota, Onqa y Taqrampa en Soras.

Para tener un buen control y desarrollar los sitios, empiezan a construir caminos, canales de irrigación, andenes y tambos porque de esa manera podía administrar adecuadamente estos territorios, sin tener ningún problema. Después de haber dominado a los soras; los incas se dividen en dos grupos para seguir conquistando territorios, uno de ellos parte con dirección a Vilcashuamán y el segundo hacia el valle de Sondondo. La ruta que tomó el último grupo fue por Kullkuncha y así sucesivamente, pasando por las faldas del nevado Qarhuarazo llegaron a Qeqa, que es uno de los territorios que forma parte del valle Sondondo, posteriormente conquistaron al grupo de los rucanas en Puquio. Después de someter y tener bajo su dominio a los rucanas, conquistan los actuales territorios de Coracora, Parinacochas y Páucar del Sara Sara; extendiéndose más tarde por Arequipa, lugar donde se encontraron con otros grupos procedentes de Cuzco. Posteriormente pasaron por Moquegua, Tacna y finalmente 
conquistaron Chile. En cambio el primer grupo, después de conquistar Soras pasó por el territorio de los Chalcos, con quienes sostuvieron una guerra y después de vencerlos se dirigió a Vilcashuamán, lugar donde fundaron y construyeron el centro administrativo más importante de la región. Los Incas no pararon, siguieron conquistando nuevos territorios, después de asentarse en Vilcashuamán, conquistó Cangallo, Totos, Paras, Huaytará y Pisco. En estos dos últimos sitios construyó centros administrativos que les permitió tener el control de los bienes y actividades que se desarrollaban entre la costa y la sierra.

\section{Patrones de Asentamiento y Características Constructivas \\ En el Periodo Inicial y Horizonte Temprano (1800 - 200 a.C.)}

Tomando en cuenta los antecedentes históricos de evolución cultural en el área andina, y teniendo evidencia arqueológica muy representativa en la región de Ayacucho, señalamos que el patrón de asentamiento de los primeros pobladores localizados en el área de San pedro de Larcay, presentan aparentemente dos situaciones diferentes, pero dan dos respuestas a un mismo proceso. En un primer caso, los primeros habitantes, instalados en las cavidades rocosas, al aumentar la población, salieron de los abrigos y empezaron a construir viviendas sobre campos abiertos, tales evidencias lo notamos en el sector de Choqepata cerca al sitio arqueológico de Doce Corrales y zonas aledañas al nevado Qarhuarazo.

En el segundo caso, es posible que siguieron habitando por largo periodo las cuevas, por lo tanto, nunca dejaron de ser ocupadas. Con la instalación de campamentos abiertos, con viviendas individuales, empezó la formación de sociedades urbano pastoriles, los grupos sociales que formaron parte de este sistema de organización, temporalmente ocupaban algunos espacios, posteriormente se mudaban a sitios cercanos para dar mayor orden y racionalizar su forma de vida, pero nunca abandonaron su territorio. De esta manera surgen los ciclos de rotación y el aprovechamiento de los recursos que abundaban temporalmente.

Entre las características de estas formaciones sociales, destacaron el pastoreo, la vida social organizada en viviendas nucleadas, la artesanía textil y la horticultura de puna.

Sabemos que en esos tiempos, la actividad principal del hombre en las punas era el pastoreo, por esta razón, para divisar los camélidos y protegerse de las fuertes lluvias y vientos, construyeron pequeños recintos de forma circular en las principales colinas; hoy en día, aun se siguen utilizando los recintos pircados con una sola hilera de piedra y sin barro. A este tipo de estructuras los pastores actuales lo denominan como "willkanas" (Ver Figura № 2).

Algunas aldeas contemporáneas en las punas, siguen ocupando los mismos espacios que habilitaron sus antepasados, los recursos y la tecnología aún no han cambiado en lo sustancial, como si el trauma de la invasión y la colonia no hubiese afectado la raíz de la tradición andina, tal como observamos por ejemplo en el procesamiento del chuño y el charqui, las construcciones tradicionales en pirca aún siguen manteniéndose. Para mudarse estacionalmente, los primeros grupos aldeanos conformados por pastores tuvieron que transitar por caminos naturales, puesto que son sistemas de enlace y comunicación entre los diferentes grupos sociales.

En cambio, asentamientos específicos correspondientes al periodo Horizonte Temprano no se ha identificado en el área de San Pedro de Larcay, pero pensamos que en Chiqnajota hay evidencias correspondientes a este periodo, puesto que se ha identificado fragmentos de cerámica con facciones muy tempranas al borde de la carretera que va a Puquio y que están en una estratigrafía muy profunda. 


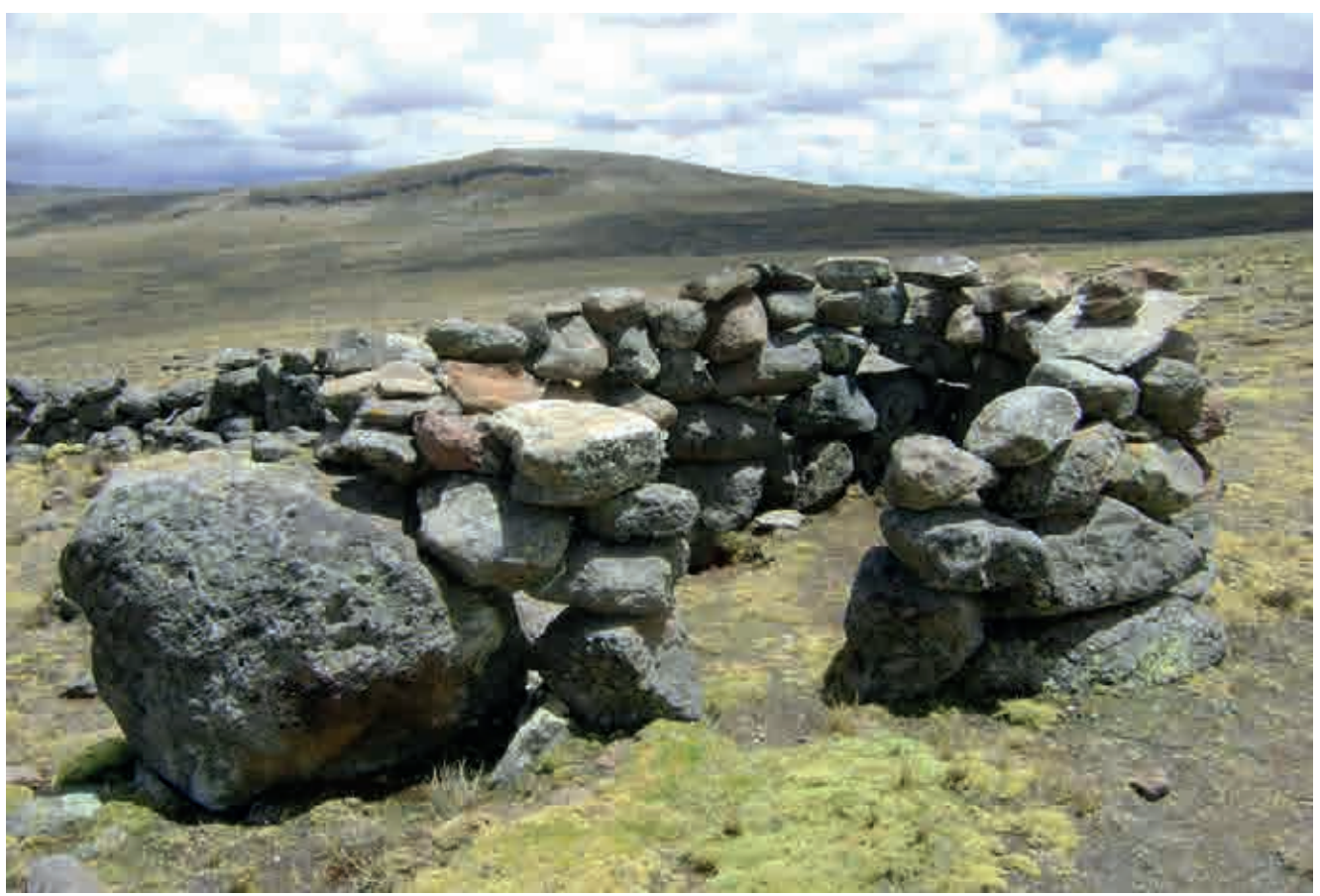

Figura № 2: Willkana utilizado por los actuales pastores de Qara Qara. (Foto: Rafael Mallco, 2009)

\section{En el Intermedio Temprano (200 a.C. 500 d.C.)}

El fenómeno social determina que las aldeas de la época Huarpa en la región de Ayacucho, como en Ñawinpuquio se conviertan en verdaderas ciudades, por ello se define una clara diferencia entre quienes vivían en las urbes y quienes vivían en el campo. Cada una tenía una ocupación y un papel en la economía de la época en la sociedad en su conjunto, quienes vivían en las ciudades; como los guerreros, sacerdotes, artesanos y comerciantes necesitan controlar al sector campesino para convertirlo en objeto de su dominación (Gonzáles y Mesia, 2001).

Los sitios Huarpa corresponden a una formación propia de la comunidad de aldea, probablemente asociada a una estructura tribal con jefaturas de diversos rangos de importancia. A diferencia de lo que ocurría en otras partes al norte de Ayacucho, en donde se configuró el sólido asentamiento de sociedades tempranas de carácter urbano.

Lo interesante es que este cambio en el patrón de ocupación territorial de los sitios Huarpa, se produjo en una etapa de grandes cambios, en otros órdenes de actividad; el más importante es el representado por la intensificación de las relaciones con la costa de Ica-Nasca, que se expresa físicamente en el desarrollo intensivo de la cerámica policroma.

Pero no solamente sucede ese tipo de cambio, lo interesante es que algunos habitantes que ocuparon las principales punas, deciden mudarse hacia los valles y ocupan las principales quebradas.

A nuestro entender los poblados Huarpa, en su mayoría serían asentamientos de casas dispersas o aglutinadas, de acuerdo con la topografía del lugar, cuya característica común es que se encuentran al borde de los campos de cultivo o dentro de ellos. Es muy característico ubicarlos en las chacras de 
los campesinos de hoy e identificarlo a partir de la cerámica que aparece en los surcos de los cultivos de papa y maíz.

Posiblemente la descomposición de la cultura Huarpa representó un evento dramático en todo sentido, pues caracteriza el tránsito de una formación predominantemente rural hacia una definidamente urbana.

A partir de los diferentes estudios analizados, se puede afirmar que los poblados de la época Huarpa estuvieron organizados sobre la base de un conjunto de aldeas ubicadas estratégicamente para el mejor aprovechamiento de los recursos naturales de la zona ocupada, y tendrían como centro principal a Nawinpuquio, que constituiría el antecedente de lo que posteriormente sería el desarrollo urbano que da origen al establecimiento de las manifestaciones de poblamiento que diferencian claramente los sectores rurales y urbanos; donde cada cual tienen actividades totalmente distintos.

El patrón de asentamiento durante el Intermedio Temprano en el Valle Chicha está caracterizado por la multiplicación de aldeas nucleadas y dispersas que se ubican cerca de las principales fuentes de agua. Todas ellas presentan la fisonomía de agrupaciones de viviendas circulares, al parecer sin organización interna, debido a la ausencia de calles y plazas. Dicha aseveración se basa en las pocas evidencias encontradas en Tororayoq y Marcalo, donde las formaciones de evidencias de recintos muestran alineamientos circulares en forma desordenada.

Además de presentar alineamientos de piedra que indiquen la presencia de muros de recintos, en Tororayoq se identificó áreas de cultivo conformados por pequeños andenes. Estas formaciones indican que la práctica de la agricultura en la época Huarpa se desarrolló cerca de las aldeas.

Dentro de la visión andina, la chacra es el centro de interrelación entre el campesino, la tierra, la semilla, el agua, la temperatura y la influencia de los fenómenos naturales y atmosféricos.

Sin embargo, la agricultura practicada cerca de las aldeas y la producción de cerámica sin un sistema de comunicación no sería fácil de desarrollarse; los caminos jugaron un rol muy importante, puesto que les permitió tener una adecuada comunicación con las distintas aldeas, así mismo dieron paso a la práctica del comercio.

Con respecto a ello, Zecenarro (2001), señala que una de las estructuras creadas en el mundo andino, cuya particularidades permiten comprender de mayor manera la concepción cosmogónica y las formas de control y territorial, es el sistema seqe y sus respectivos controles de huacas, entidades inseparables que formaron un organismo que aglutinó a la infraestructura socio-económica y a la superestructura ideológica de un solo binomio.

Para Ravines (1989), los caminos de la época prehispánica se pueden clasificar en naturales, artificiales y herradura, en cambio para Pérez (2003), los caminos se clasifican en tres clases: caminos empedrados, caminos empedrados con graderías y senderos.

\section{En el Horizonte Medio (500 a 900 d.C.)}

Durante el Horizonte Medio los asentamientos de la época Huari en el valle Chicha se caracterizan por tener una planificación urbana, posiblemente tuvieron sus antecedentes en la cultura Huarpa con la construcción de Ñawinpuquio. Este fenómeno urbano, también se ve reflejada en otros sitios provinciales del Horizonte Medio. Las evidencias más resaltantes de planificación lo encontramos en Sillacha, Yako, Chiqnajota y Kallpa, en los sitios mencionados no se encuentra arquitectura monumental como en la capital de Huari, sin embargo, la distribución espacial es similar y corresponde a épocas mas tardías. 
Algunos investigadores dicen que el urbanismo debe ser tomado a partir de una serie de factores como son la nucleación, el establecimiento de áreas productivas diferenciadas, donde la planificación no debería tener peso alguno, ya que ésta aparece tardíamente en el viejo mundo (Gonzáles y Mesías:2001). En cambio Williams señala que la arquitectura y urbanismo Huari da cuenta de la operación de una forma de gobierno centralizado que conduce procesos y que maneja normas y reglas operativas concretas. En su versión expansiva la arquitectura que acompaña a esas formas de ocupación responde a patrones claramente establecidos que cumplen instrucciones predeterminadas, no obstante, la construcción de centros urbanos mayores fue acompañada por numerosos asentamientos de dimensión y complejidad menor. Los de tamaño intermedio contienen los mismos recintos cercados con cuartos angostos adosados a los muros, que son típicos de las ciudades mayores y que presentan, sin duda indistintamente viviendas de los funcionarios y administradores, depósitos y áreas protegidas para administración y el trabajo. Algunas también tienen edificaciones dedicadas al culto, mientras que otros asentamientos son simples cercados mayores de traza geométrica y muy poca densidad de construcción, estos generalmente responden a conglomerados urbanos que mantienen formas locales de trazado y edificación.

Los sitios arqueológicos del Horizonte Medio en el valle Chicha no presentan evidencias de una centralización política o de una elite bien definida, más bien representan a un centro provincial integrado por los habitantes locales. Pese haber denominado a Sillacha como uno de los primeros sitios habitados por los huaris, la mayor cantidad de evidencias arquitectónicas se encuentra en Chiqnajota, Yako y Kallpa. Cuando los huaris se asentaron en el valle Chicha no solo optaron por construir recintos, sino que para desarrollarse también construyeron plazas, edificaron espacios sagrados, utilizaron las principales concavidades rocosas, construyeron caminos, fortificaron áreas de defensa y por último construyeron gran cantidad de andenerías para la agricultura.

En Chiqnajota, la evidencia arqueológica perteneciente al Horizonte Medio se encuentra debajo de las estructuras circulares construidas en épocas tardías y están localizadas en el segundo sector del sitio arqueológico. El espacio ocupado comprende una pequeña hoyada, en ella se encuentra plazas y recintos de traza ortogonal asociados a corredores que conducen a posibles galerías, además, por el tipo de arquitectura estos recintos pertenecerían a la época 2 del Horizonte Medio. Los Huari para tener una adecuada administración de Chiqnajota, construyeron recintos muy altos de aproximadamente 5 metros de altura, los cuales se encuentran asociadas a plazas y formaciones monticulares de carácter ritual (Ver Figura $N^{\circ} 3$ ). En Chiqnajota también se localizaron las cabeceras de los muros que forman espacios abiertos de mucha importancia que están intercomunicados por corredores muy estrechos que conducen a posibles galerías subterráneas que se encuentran en regular estado de conservación. (Ver Figura Nº 4, 5 y 6).

Por nuestra parte, al igual que en Chiqnajota, en la cima del primer sector de Qasamarca identificamos aberturas que posiblemente conducen a galerías subterráneas, en las aberturas se identificó restos óseos humanos que indican su uso como tumbas. El patrón de plataformas sobre elevadas y galerías subterráneas construidas en la cima de los cerros, fue registrado en el valle alto de Nepeña por Proulx (1985: 285), quien señala que el sitio de Huancarpón es el mayor centro Recuay con influencia serrana en el valle.

En el sitio de cerro Las Monjas de Marcahuamachuco fue identificada un edificio largo y angosto denominado "galería". Generalmente se divide en cuartos, cada uno con su propia puerta. Estas puertas se encuentran, en su mayoría, en una de las dos fachadas largas, mientras que la otra rara vez la tiene (Topic y Lange, 2000:187). 
Otra de las evidencias muy significativas en Chiqnajota es la presencia de dos pequeños recintos de forma circulares que pudieron haber servido como depósitos de alimentos y es posible que su uso se haya prolongado hasta la época Inca (Ver Figura $\mathrm{N}^{\circ} 7$ ).

Cerca de estos recintos, al sur de la plaza principal se encuentran distribuidos un conjunto de andenes que indican la práctica de la agricultura cerca de la población, esta forma de usar la tierra ha sido heredado por sus antecesores huarpas. La presencia de los dos recintos que pudieron servir de almacén, es la única evidencia localizada en la cuenca del río Chicha Soras.

Schreiber (1991) identifica dos recintos parecidos en la cuenca del Qarhuarazo y teoriza que podrían haber sido utilizados para almacenaje, pero admite que efectivamente ignora la forma arquitectónica de posibles depósitos Huari. Sin embargo Isbell (1997), sostiene que dos cuartos pequeños en el recinto de Qargampata eran depósitos.

También se encuentran ambientes circulares en distintos sectores de Huari que posiblemente servían como depósito de alimentos, junto a este tipo de construcciones existen pequeños cuartos y muros protectores a manera de circunscribir un área (Gonzáles y Mesía, 2001: 40).

La interrelación entre andenes y almacenes, indican un buen manejo del sistema económico en los centros provinciales de la época Huari. Esta funcionalidad se completa con adecuado sistema de comunicación, por ello, los habitantes de Chiqnajota construyeron caminos que conducían a las principales punas (Ver Figura $N^{\circ} 8$ ).

La existencia de redes de caminos Huari probablemente resulta más claras en las provincias que en el núcleo (Lumbreras, 1974; Schreiber, 1984 y 2000).

Los andenes Huari localizados en el valle Chicha presentan plataformas casi planas sostenidas por muros de contención en forma vertical y no siempre tiene riego o piedras menudas para buen drenaje. Detrás del muro de contención el talud generalmente hay piedras sueltas grandes para lograr un drenaje seguido por un relleno de suelo para el cultivo de un espesor de $50 \mathrm{~cm}$ aproximadamente, la gradientes del terreno muchas veces no se han nivelado por ello es inclinado. También durante el Horizonte Medio los Huari que ocuparon el área del valle Chicha, controlaron y tuvieron un adecuado manejo del agua, por esta razón construyeron reservorios que les permitía almacenar agua y de esa manera irrigar sus terrenos agrícolas, Layme Qocha es una de las evidencias más resaltantes de la práctica del control del agua.

Cuando los ocupantes de Chiqnajota morían eran enterrados en chullpas y en tumbas tapadas con grandes bloques de piedra, parece que los principales personajes fueron enterrados cerca de la población, mientras que los secundarios eran trasladados al promontorio de Obrajería, en este lugar se identificó restos de pequeñas estructuras circulares asociados a óseos humanos y a cerámica del estilo Ocros; no obstante, este último sitio no solo fue utilizado como cementerio, sino que también como centro de defensa; es por ello que presenta un sistema de fortificación con banquetas internas destinadas para una visualización muy particular del sitio, los muros fueron construidos estratégicamente y presentan una altura aproximada de cuatro metros (Ver Figura $\mathrm{N}^{\circ}$ 9). En la cima del promontorio natural se localizó acumulación de grandes bloques de piedra que indicaría su utilización ante los eventuales ataques de los enemigos, posiblemente ante un eminente ataque los bloques de piedra serían arrojados contra los enemigos, al ver la peligrosidad se retiraban y no causaban ningún daño en Chiqnajota (Ver Figura $N^{\circ} 11$ ). Otro de los sitios representativos en la cuenca del río Chicha es Yako, se caracteriza por tener recintos de forma circulares que tienen 7 y 8 metros de diámetro, los cuales están asociados a formaciones de terrazas, junto a ello también se identificó recintos circulares pero 
de menor tamaño, estos últimos pertenecen al Intermedio Tardío; por lo tanto no debemos confundir las evidencias del Horizonte Medio con los del Intermedio Tardío, puesto que difieren en tamaño y en la técnica constructiva. Yako no solo está conformada por recintos circulares, sino también por espacios planificados que están situados detrás del montículo naranja, además en la parte baja del primer sector donde está la planicie, se identificó recintos abiertos de forma cuadrangular, los cuales están asociados a formaciones de terrazas. Cuando se observa detenidamente desde el montículo naranja, se nota las cabeceras de los muros que presentan un adecuado ordenamiento espacial. Las escasas evidencias que se encuentran sobre la superficie nos indican la utilización del espacio a partir de la época 1B del Horizonte Medio, puesto que la época 1A está representada por rasgos tiahuanacoides y lo encontramos en la capital Huari.

Cerca a uno de los recintos que se encuentran en la parte baja del sitio, se identificó cabeceras de muros de traza ortogonal y los materiales utilizados para su construcción presentan evidencias de tallado. En la colina principal de Yako, cerca de la plazoleta de forma alargada, se encuentra una estructura en forma de "D", asociada a pequeños recintos de forma cuadrangular en su parte posterior. En el mismo sitio de Yako, Frank Meddens y Anita Cook identificaron un templo en "D", (Meddens y Cook, 2001: 213), pero se encontraría en el tercer sector y estaría en mejor estado de conservación a comparación de lo que hemos identificado. Este tipo de templo fue hallado por primera vez en 1984 por Mario Benavides, en el sector Cheqowasi de Huari. El interior de la pared en los edificios en "D" de Yako identificados por Meddens muestran la pared del nicho un solo enlucido de barro y sería el único caso en el valle Chicha-soras, a pesar de que parece estar asociado con algunas estructuras conocidas en el valle de Ayacucho (Meddens y Cook, 2001: 216).

Por las características que menciona, no sé si la estructura semi circular identificada y excavada por Meddens representa a un posible templo en "D", puesto que también en el mismo sitio se identificó 6 recintos grandes con las mismas características, no creo que se trate de un lugar donde se construyeron varios templos, más bien estos recintos pudieron tener otra funcionalidad, lo que si estamos convencidos es la presencia de un templo en "D", pero se encuentra en la terraza principal asociado a una plazoleta de forma alargada en su lado suroeste.

Los templos con planta en forma de "D" parecen constituir la estructura ceremonial asociada con la nueva religión que apareció en Ayacucho a comienzos del Horizonte Medio, mientras que anteriormente la transformación religiosa era vinculada solo con la recién introducida iconografía tiahuanacoide (Isbell, 2000: 22). El sitio Vegachayoq, que sus investigadores llaman Templo Mayor (Bragayrac, 1985; Gonzáles Carré y Bragayrac, 1999) seguramente responde a una arquitectura pública religiosa que construyeron los Wari dentro de la traza irregular de su ciudad; este edificio presenta planta en forma de una "D" (Williams, 2001: 71). Los edificios en forma de "D" fueron probablemente estructuras ceremoniales o templos. Más aún, parecen ser los únicos en Ayacucho durante el final de las fases Vista Alegre y Ocros (Isbell, 2001: 115).

En Yako, también se encuentra un conjunto de andenerías que están asociadas a pequeños caminos. En sus estudios Kendall (2005), menciona que los andenes en Qasa-Larcay son construidos en estratos múltiples; con riego, sutil inclinación para la distribución del agua, con la base excavada y rellenada de piedras, cascajo y encima de este un metro de tierra agrícola. Los muros de contención consisten en piedras con amarres y mayormente de dos caras. Por otra parte, Meddens (1999) señala que la andenería visible en Yako parece fechar a lo más temprano de la Época 2 del Horizonte Medio o a una época más tardía del Horizonte Medio. Otra de las evidencias resaltantes en Yako es la presencia de una plazoleta de forma circular situada en la cima del montículo naranja, dicha plazoleta fue cerrado con un mediano muro que bordea su perímetro, además en las partes subsiguientes que 
corresponden a otros niveles se identificó otros muros que rodean al montículo y adquieren la forma de una pirámide circular y por las características que presenta, el espacio pudo ser utilizado con fines rituales. No obstante, en el lado norte de la pirámide circular se encuentra espacios abiertos de forma cuadrangular asociados directamente al montículo naranja, por la forma y distribución de los espacios abiertos, se trataría de un lugar destinado para actividades públicas (Ver Figura $\mathrm{N}^{\circ} 12$ ). El Horizonte Medio en la cuenca del río Chicha, también se caracteriza por la utilización de las principales concavidades rocosas con fines de enterramiento, dentro de los cuales se construyeron cámaras funerarias divididas hasta en tres niveles. El cementerio de Kallpa es una de las evidencias más resaltantes, los espacios funerarios construidos presentan divisiones a manera de pequeños cuartos o cámaras funerarias de formas cuadrangulares, las tumbas presentan enlucidos de barro, aplicaciones de pintura y hay una clara evidencia de una constante reutilización, esta forma de cuidar los espacios funerarios nos indican que los huaris en el valle Chicha-Soras dieron un especial trato a los muertos y por ello buscaron un lugar apropiado para su descanso y veneración (Ver Figura N 13 y 14).

En Marcalo también se localizó en medio del abismo una concavidad rocosa utilizada con fines de enterramiento, por su ubicación probablemente perteneció a un personaje muy importante, en cambio las cuevas de Turkuymalla presentan evidencias de la práctica de entierro colectivo, las concavidades han sido cerradas por muros que alcanzan la abertura de la roca (Ver Figura $\left.N^{\circ} 15\right)$. Es probable que los cuerpos enterrados fueron depositados secuencialmente con finos textiles y acompañados de sus respectivas osamentas, es por ello que durante nuestra visita a este lugar identificamos fragmentos de tapices Huari, soguillas trenzadas de fibra vegetal, un collar con cuentas de conchas y abundantes restos óseos humanos que están desarticulados y las tumbas completamente profanadas.

En Soqia, también se identificó concavidades rocosas que contienen abundante cantidad de restos óseos humanos y presentan similar uso a las cuevas de Turkuymalla (Ver Figura $\mathrm{N}^{\circ} 16$ ), y según los comentarios de los pobladores, de este sitio se habría recuperado importantes evidencias arqueológicas como vasijas de cerámicas, restos de tapices y una momia "Micaela", que fueron almacenados en el colegio del lugar, pero que posteriormente de manera misteriosa estas desaparecieron. Los materiales arqueológicos identificados en superficie nos indican que el sitio fue muy intensamente utilizado durante el Horizonte Medio y posiblemente haya algún sector donde se encuentre evidencia intacta, puesto que las características de formaciones de terrazas por toda el área, indican la práctica de actividades agrícolas muy ligadas a ceremonias religiosas y rituales que se practicarían desde épocas muy tempranas, puesto que en algunos sectores se han identificado montículos de basura que contienen talla de material lítico y fragmentos de cerámica de facciones tempranas.

Finalmente, durante la época Huari la construcción de centros urbanos mayores fue acompañada por numerosos asentamientos de dimensión y complejidad menor, los de tamaño intermedio contienen los mismos recintos cercados con cuartos angostos adosados a los muros que son típicos de las ciudades mayores y que presenta sin duda indistintamente viviendas de los funcionarios y administradores, depósitos y áreas protegidas para administración y el trabajo. Algunas también tienes edificaciones dedicadas al culto, otros asentamientos son simples cercados mayores de traza geométrica con muy poca densidad de construcción, estos generalmente responden a conglomerados urbanos que mantienen formas locales de trazado y edificación (Williams, 2001: 63).

\section{En el Intermedio Tardío (900 - 1476)}

El patrón de asentamiento correspondiente a los grupos étnicos locales no presentan sistemas de planificación, los Chichas y los Soras al igual que otros pueblos Chanca de la región de Ayacucho nunca vivieron en ciudades, sino más bien se orientaron a una vida rural y campesina organizada en pequeñas aldeas o pueblos, constituyendo aldeas dispersas localizas en la cima y ladera de los cerros. Al 
parecer la ausencia de un poder político habría determinado la fricción entre un conjunto de pueblos que mantenían ciertas unidades culturales integradas geográficamente en las cuencas y subcuencas, sin duda estos problemas sociales dio origen a pueblos fortificados, que manifiesta tiempos de violencia y guerra entre grupos étnicos.

Los grupos étnicos pertenecientes al Intermedio Tardío, por lo común en las zonas bajas, cercana a los ríos, no edificaron sus pueblos, porque la naturaleza agreste de esas cuencas, en cierta manera impedía realizar trabajos constructivos, aunque si comprendemos que ellos vivieron alertas a la defensa de sus territorios, los sitios bajos no eran lugares estratégicos para enfrentar cualquier tipo de disputa (Ruiz, 2004: 45).
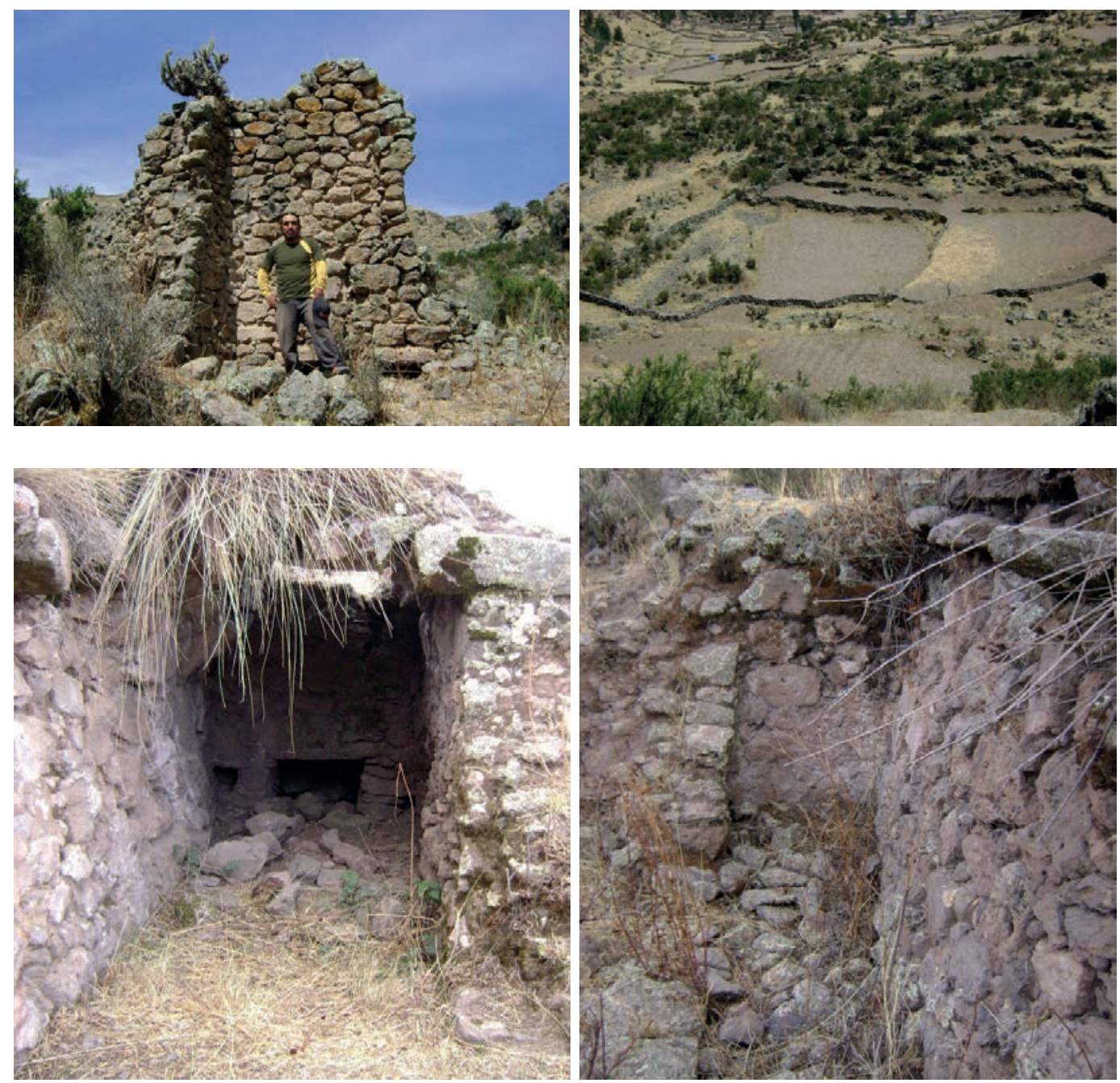

Figura № 3, 4, 5 y 6. Superior izquierda: Arquitectura Huari de Chiqnajota. Superior derecha: Plaza principal de Chiqnajota. Inferior izquierda: Corredor principal de Chiqnajota. Inferior derecha: Continuación del corredor que comunica con galerías subterráneas. (Fotos: Rafael Mallco, 2009). 

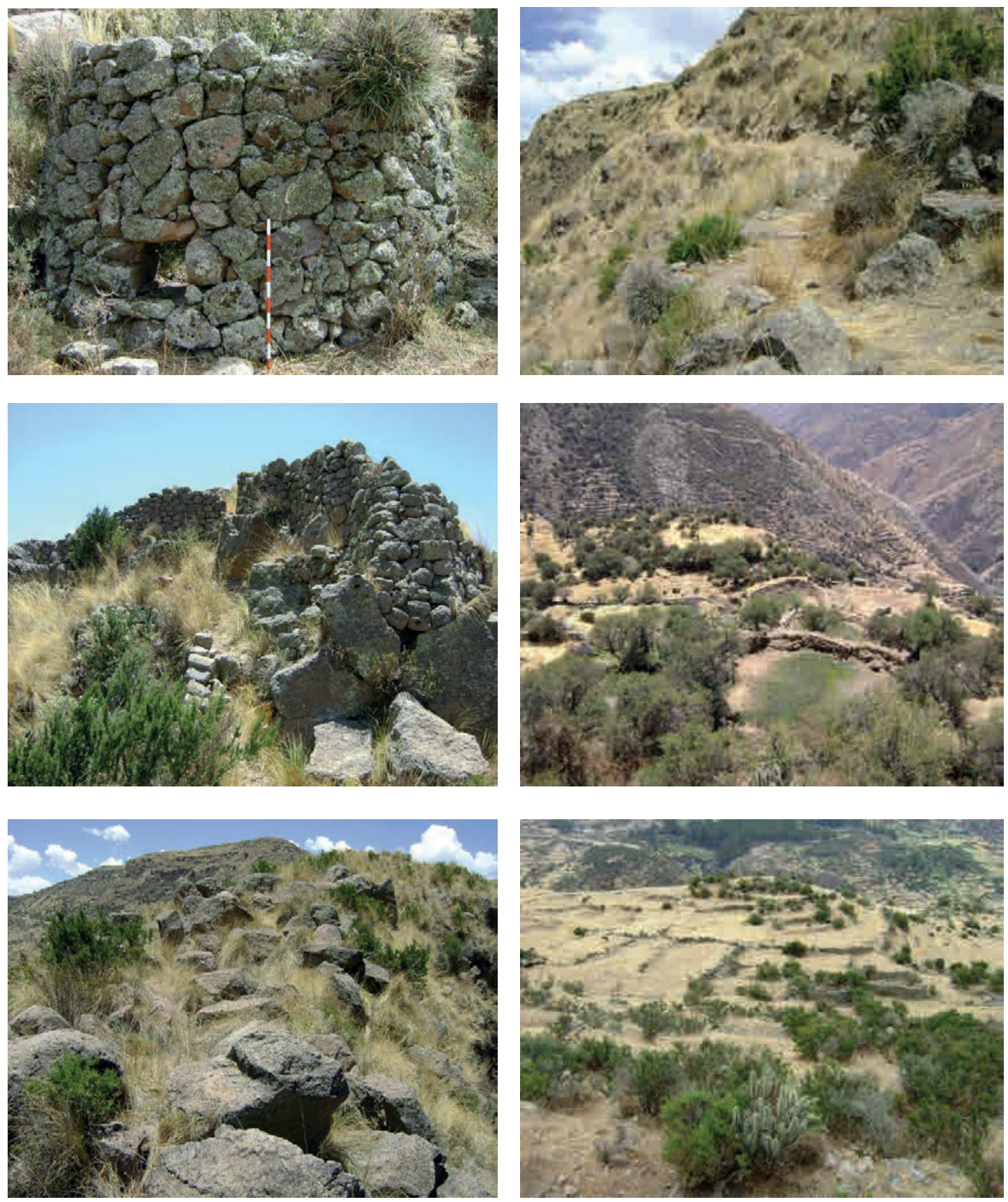

Figura № 7, 8, 9, 10, 11 y 12. Superior izquierda: Depósito circular identificado en Chiqnajota. Superior Derecha: Camino Huari que parte de Chiqnajota hacia las punas de Cara Cara y Puquio. Central Izquierda: Muralla de defensa y fortificación principal de Obrajería. Central Derecha: Reservorios Huari de Layme Qocha. Inferior Izquierda: Alineamiento y acumulación de bloques de piedra en la cima del promontorio Obrajería. Inferior Derecha: Pirámide ceremonial de forma circular identificada en Yako (Fotos: Rafael Mallco, 2009). 

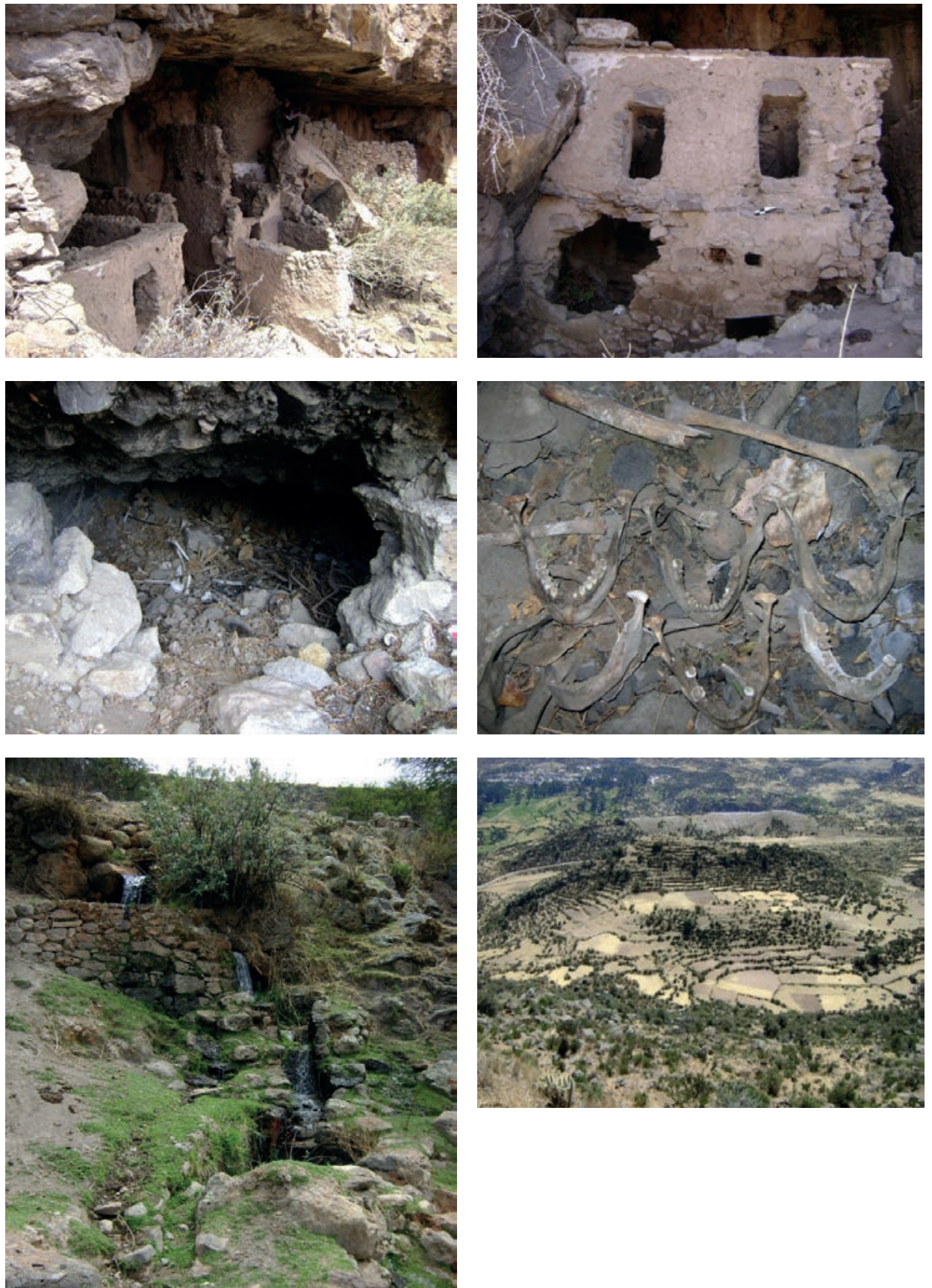

Figura № 13,14,15,16, 17 y 18. Superior Izquierda: Cementerio Huari de Kallpa. Superior derecha: Cámaras funerarias disturbadas en Kallpa. Central Izquierda: Restos óseos humanos al interior de la cueva de Turkuymalla. Central Derecha: Restos óseos humanos identificados al interior de la cueva de Soqia. Inferior Izquierda: Canales prehispánico de Layme Qocha. Inferior derecha:

Distribución de andenes en el lado noroeste de Tayapukro. (Fotos: Rafael Mallco, 2009). 
El patrón de asentamiento y arquitectónico, sufrieron un cambio sustancial por una nueva concepción en la utilización del espacio, renunciado la vida urbana planificada para dar paso a un conglomerado de habitaciones sin orden aparente. El criterio de uso de espacio durante la época Chanka parece que fue tomado de manera forzada, debido a la situación del problema social que surgió luego del ocaso Wari, quizá por ello llegaron a escoger los terrenos ubicados en zonas elevadas y lugares escarpados, aprovechando como una forma natural de carácter defensivo (Vivanco, 1998: 178).

El patrón de construcción de las viviendas circulares y la organización de unidades domésticas con un patio de actividad cotidiana, iniciados durante el formativo, continuó como una tradición regional hasta los periodos tardíos. El criterio que cambió sustancialmente fue la preferencia en la selección de los espacios físicos. A medida que fue aumentando la presión poblacional, la demanda de bienes y servicios también fue creciendo y, para regular los mecanismos de respuesta a la demanda, la sociedad fue obligada a asumir nuevas formas de organización socio-política. Como parte del nuevo orden social y económico, los asentamientos que surgieron hasta el final de este periodo se emplazaron a lugares estratégicos y visibles, ubicándose de esa manera en la cima de los cerros (Matos, 1994:65)..

En el valle Chicha- Soras los principales sitios Huari fueron reocupados y habitados por grupos étnicos locales y chancas que conllevaron al abandono del patrón de urbanismo para dar paso a un conglomerado de habitaciones sin orden alguno y este tipo de evidencias podemos identificar en Chiqnajota, Yako, Karpani y Taqrampa (Ver Figura № 19). Se nota claramente que la esencia del ordenamiento espacial se perdió después de la decadencia Huari y como consiguiente surge la práctica de una vida más agitada tal vez por la turbulencia política que les tocó vivir y como consecuencia de ello surge la ocupación de las principales montañas o puntos más altos de cada valle con la finalidad de poder tener el control de los espacios circundantes y estar en alerta al ataque del enemigo.

Si bien no existe un estricto plan de urbanismo en los sitios tardíos del valle Chicha, sin embargo, en cada caso se encuentra un esquema de organización similar que implica un cierto número de elementos comunes cuidadosamente adaptados a la topografía particular de cada sitio. El hábitat se extiende a los al rededores de los patios centrales y está constituido por edificios circulares dispuestos en pequeños grupos ovales, encerrando un espacio libre, al cual Lavallèe y Julien (1983), lo denominó como unidades alveolares. Según su concepción las unidades alveolares comprenden frecuentemente siete $\mathrm{u}$ ocho construcciones de recintos que giran alrededor de un pequeño patio (Ver Figura № 20).

En nuestra zona de estudio, las construcciones arquitectónicas tardías de Chiqnajota, Puka Orqo, Raqayniyuq, Obrajería, Yako, Qasamarca, Karpani y Pulluway, constan de una pieza única, con una sola entrada. Las formas circulares de los recintos, por lo general se adaptan a la configuración del terreno, y los edificios adosados a los muros de contención o formaciones rocosas, frecuentemente son irregulares y posee un diámetro que varía de 3 a 5 metros. Todos los asentamientos tuvieron ubicación estratégica, con una amplia visión de entorno.

El modelo de organización del espacio se asemeja mucho a un panal de abejas, con estrechos y sinuosos pasadizos para el transito interno. Hay recintos que están completamente aglutinados, pero también hay edificaciones dispersas lo cuales responden básicamente a la configuración del terreno. Por las características que presentan estas instalaciones deben haber sido construidas sólo para uso y acceso de la gente, pues no hay indicios que permitan suponer el ingreso de animales. Los caminos internos sólo permitieron el tránsito de gente caminando en fila, sin la opción de hacerlos en grupos abiertos. La plaza o patio principal de estos asentamientos generalmente se ubican en la cima de los sitios y son de formas circulares o semicirculares rodeadas por una fila de piedras, estos espacios fueron posiblemente de uso público y ceremonial, puesto que asociado a ellos en las pendientes de 


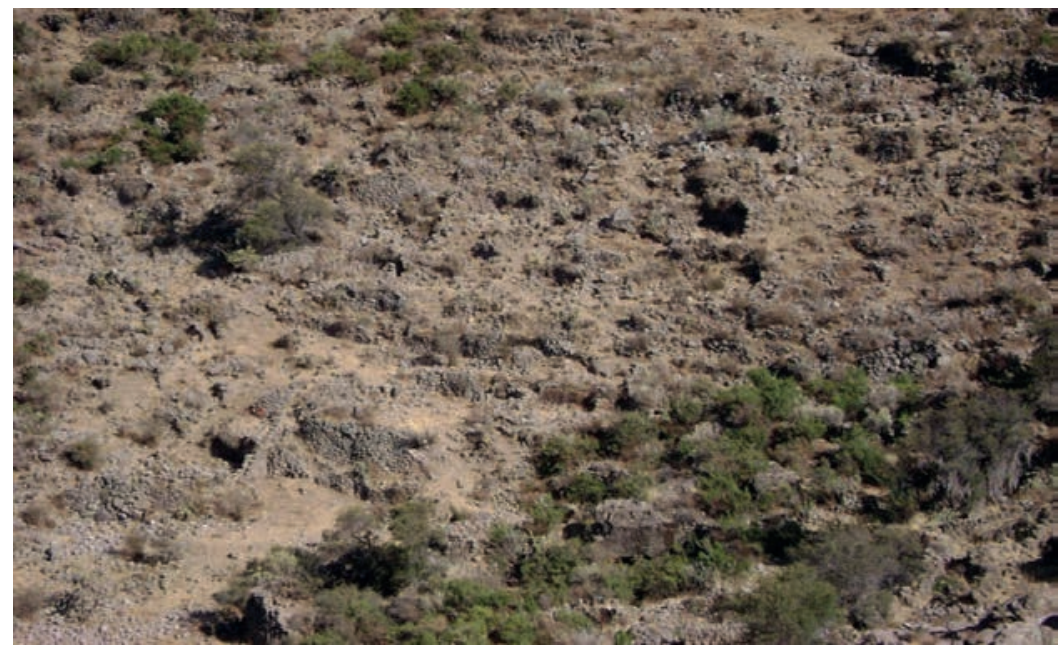

Figura $N^{\circ} 19$. Recintos del Intermedio Tardío en el sitio arqueológico de Chiqnajota. (Foto: Rafael Mallco, 2009).

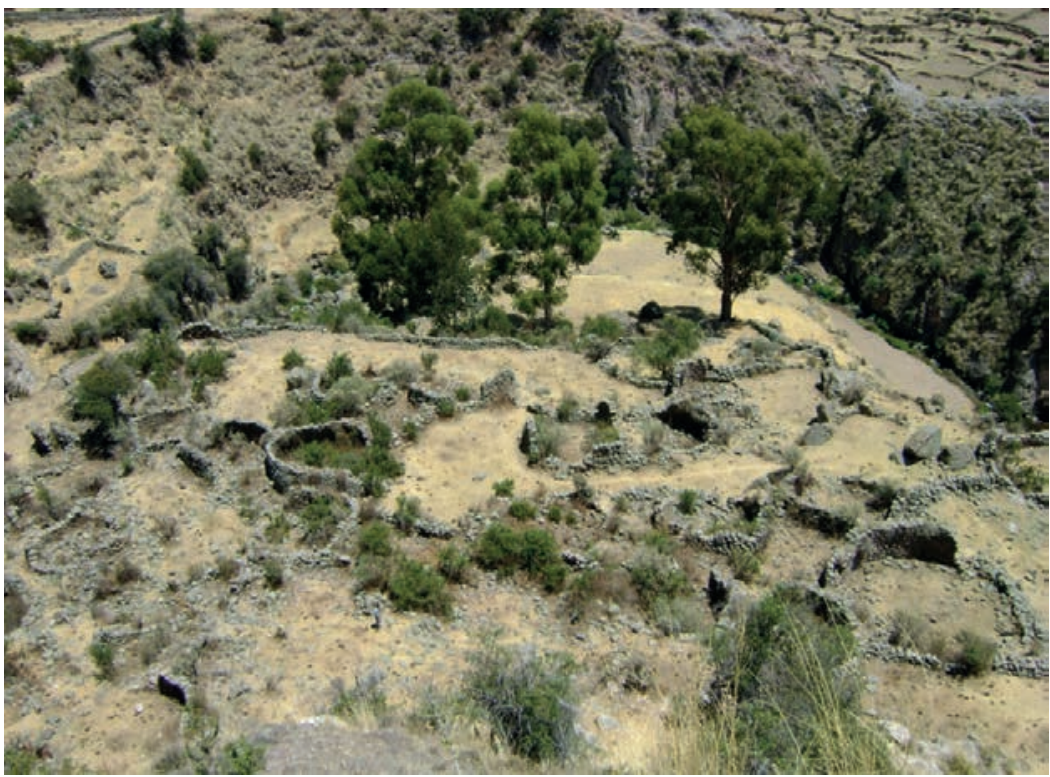

Figura $N^{\circ} 20$. Recintos circulares asociados a pequeños patios en Raqayniyuq. (Foto: Rafael Mallco, 2009).

la ladera de los cerros se identifica abundante fragmentos de cerámica decorada y no decorada de facciones tardías. También hay pequeños patios al interior de los asentamientos, pero estos más bien parecen haber sido utilizados como medio de tránsito hacia las diferentes viviendas. En realidad el tránsito interno se efectuaba a través de estrechos pasadizos y en pocos casos existe un espacio abierto en medio de las edificaciones; posiblemente fue habilitado como patio. 


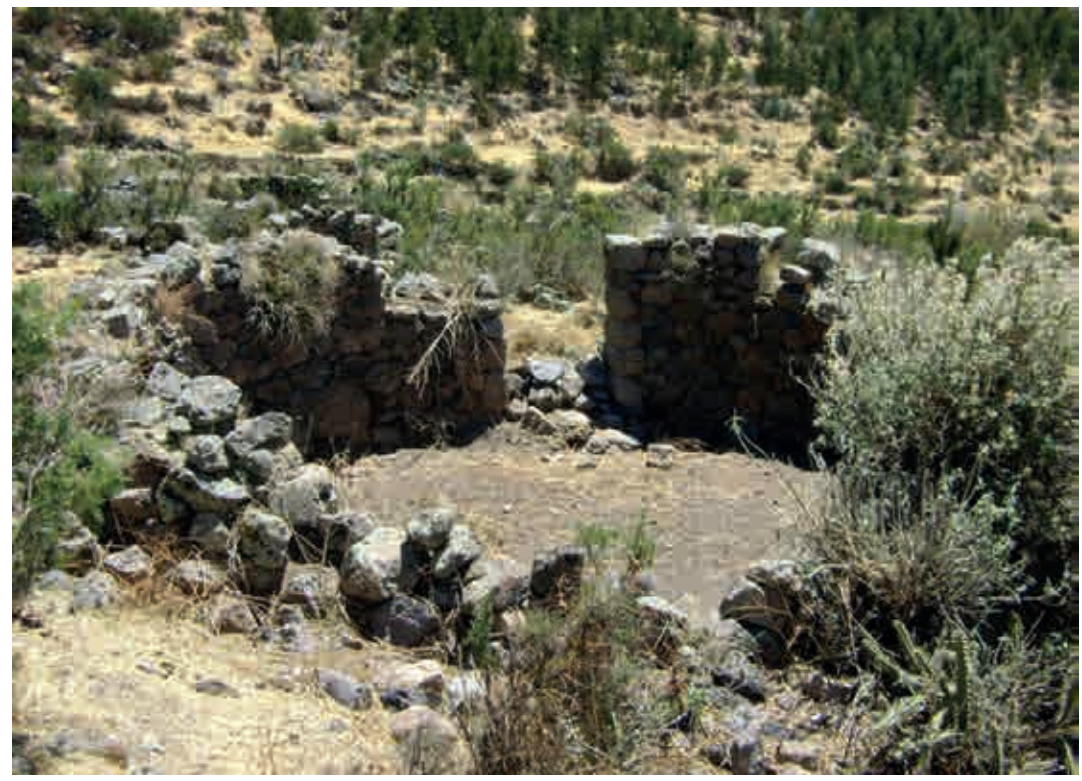

Figura $N^{\circ} 21$. Característica típica de un recinto tardío en el valle Chicha-Soras. (Foto: Rafael Mallco, 2009).

Los sitios construidos en las cumbres de los cerros, llama poderosamente la atención el adelanto técnico alcanzado en la arquitectura, hasta dominar la agresión de las rocas y adosar armoniosamente las paredes sobre ellas. Con maestría e ingenio, se lograron amarrar las construcciones sobre los farallones y algunas construcciones rocosas, a manera de balcones que miran al fondo de las quebradas.

La visión de la cultura material, nos aproxima a formarnos la idea de una sociedad que vivió en difíciles circunstancias de guerra y conflicto, ya que la ubicación estratégica y defensiva de sus poblados y viviendas así lo sugieren. Por otro lado, los poblados no presentan ningún tipo de diferencia en la arquitectura, que suponga la existencias de clases sociales claramente diferenciadas; por el contrario, las edificaciones tienen características homogéneas (Gonzáles, 1992: 36). De la misma forma la cultura material nos indica que los grupos étnicos como los Chichas, Soras, Chalcos, Rucanas y Antamarcas al igual que otros grupos vecinos étnicos tuvieron sus propias formas de elaboración y producción de cerámica, tal vez por encontrarse en una situación difícil no les ayudó a producir una cerámica pictórica, sin embargo, representaron a personajes posiblemente de mucha importancia. Los fragmentos de cerámica tardía identificada en el área de Larcay está representados por grupos cerámicos de tipo Tanta Orqo, Qachisqo, Arqalla, Aya Orqo, Chicha y Soras.

La cerámica del grupo Tanta Orqo se encuentra en gran parte de los sitios identificados, pero la mayor concentración se encuentra en Chiqnajota y Qasamarca, también hemos encontrado cerámica Tanta Orqo en Obrajería, Raqayniyuq, Puka Orqo, Onqa, Yako y Karpani, pero en menor cantidad. La cerámica Tanta Orqo en el valle del río Chicha se caracteriza por tener una pasta de color naranja, el engobe es de color rojo y no presenta un buen acabado. Está confeccionado mediante la técnica del modelado, presenta bandas de color negro que rodea el cuerpo de las vasijas, estas pueden ser en número de dos y hasta tres, los cuales están separadas por un espacio ancho pintado con blanco, crema 


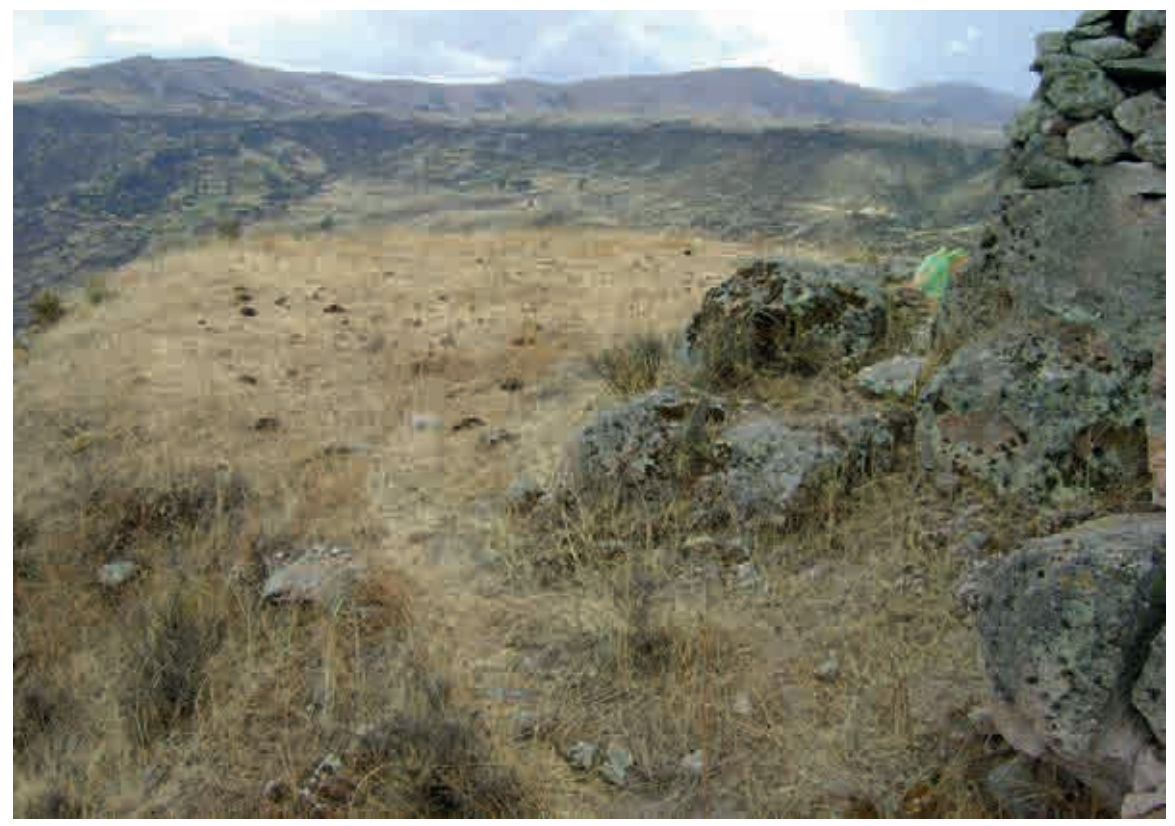

Figura $N^{\circ} 22$. Localización de una plazoleta en la cima del promontorio Qasamarca. (Foto: Rafael Mallco, 2009).

o naranja, sobre los cuales se encuentran diseños en forma de semillas con líneas negras al centro, en algunos casos parece representar círculos alargados que parecen un ojo y en otros fragmentos aparecen diseños en forma de hojas y eslabones entrelazados en la superficie exterior de las vasijas, mientras que la parte interna no presenta pintura. Los colores usados son rojo, negro, marrón, gris, blanco, crema y naranja, por consiguiente, todos estos colores no se aplican en una sola vasija, son cambiantes.

Las formas están representadas por cuencos, ollas, cántaros y platos. Los cántaros poseen bordes evertidos y en la parte externa se encuentra pintura de color negro. Las asas son cintadas en posición vertical.

En cambio la presencia del estilo Qachisqo en nuestra zona de estudio es poco y se encuentran principalmente en los sitios de Qasamarca y Chiqnajota, su poca presencia nos hace suponer, que este grupo cerámico llega al valle de Chicha mediante el comercio, por lo tanto no tuvo notable influencia, en vez de ello, se desarrolló otro estilo de carácter local a la que denominamos como estilo Chicha. La cerámica Qachisqo identificada en la cuenca del río Chicha se caracteriza por tener una pasta de color naranja pálido y rosáceo, algunos fragmentos de las vasijas presentan engobe diluido de color naranja, mientras que otros fragmentos no presentan engobes, por lo tanto su función pudo ser de uso doméstico. Los diseños están compuestos por pequeñas bandas mal delineadas y son de color rojo y negro. Las formas predominantes son platos, cántaros y ollas. Las asas son cintadas y se encuentra en posición vertical sobre el diámetro mayor del cuerpo. El cuello de los cántaros presenta una cara gollete y están decorados por pequeñas aplicaciones de arcilla, formando pequeños botones con incisiones que da la forma de una cara humana con los ojos achinados o jalados. 
Los fragmentos de cerámica del estilo Chicha se identifican en todos los sitios identificados y se encuentran asociados a los recintos y estructuras funerarias. La mayor concentración de cerámica correspondiente al estilo Chicha se encuentra en Chiqnajota, Onqa, Raqayniyoq, Obrajería, Qasamarca y Karpani. La concentración en los declives de Obrajería nos hace suponer que fueron rotos exprofesamente, probablemente debido a la práctica de actividades rituales, de no ser así, sería producto de un enfrentamiento bélico entre los Chichas y los Soras.

La cerámica del estilo Chicha está conformada por una pasta de color naranja, los engobes son de color rojo y guinda. Entre las formas destacan cántaros con base mamiforme, cuerpo globular, paredes convexas, el cuello ligeramente expandido y el borde evertido. Hay fragmentos de cántaros que poseen cuerpo globular, cuello directo, y el labio redondeado.

No se ha encontrado presencia de asas, si hay son de forma cintada puestas en posición vertical sobre el cuerpo de los cantaros y ollas. También existen cántaros con cara gollete, el cuello del cántaro es recto. La representación de cara humana presenta incisiones y aplicaciones de arcillas, en sus lados en vez de orejas presentan delgadas asas cintadas ubicadas verticalmente. Los platos tienen base redondeada, con las paredes ligeramente convexas y las ollas presentan el cuello evertido, posiblemente con dos asas y la base convexa. Los fragmentos de los vasos nos indican que tiene los labios redondeados y el borde evertido. La mayoría de los fragmentos identificados no presentan decoraciones y en algunos se encuentra una banda horizontal de color negro cerca al gollete de los cántaros. Otro tipo de cántaros están conformados por caras humanas modeladas sobre el ángulo exterior del cuello, la representación del rostro humano es muy pequeño a comparación del primero. El engobe de color rojo y guinda es aplicado en la superficie interna y externa de las vasijas y otros especímenes solo en la superficie exterior.

El otro grupo de cerámica identificada en el área es del estilo Soras, el cual se caracteriza por ser vidriada o vitrificada. Meddens (1999), es el primero en identificar el estilo Soras y lo describe como una cerámica vitrificada. Por su denominación nos hace pensar que él se refiere como estilo Soras a un grupo de cerámica que pudo encontrar en el sitio arqueológico de Taqrampa que es un poblado prehispánico que se encuentra al sur de la localidad de Soras.

Con la visita al sitio se ha podido constatar que material descrito por Meddens se encuentra en menor proporción que en otros sitios del valle Chicha - Soras. Por lo tanto la mayor concentración de cerámica correspondiente al estilo Soras se encuentra en los sitios de Chiqnajota, Onqa y Raqayniyoq en el anexo de Chicha. Sin embargo, en Qasamarca, yako, Karpani y Marcalo se encuentra en menor proporción al igual que en Taqrampa de Soras.

Por nuestra parte deducimos que el estilo Soras es una variante tardía del estilo Chicha y que permanece incluso hasta la época Inca. Cuando se realizaba la prospección del área observamos que la característica de la cerámica vitrificada se debe a un exceso de temperatura en la cocción probablemente sobre los $1000^{\circ} \mathrm{C}$. Lo cierto es que la cerámica adquiere una apariencia grisácea y es poco diferenciable en el suelo, parece restos de piedras de origen volcánico. Las tonalidades de la pintura cambian y se nota claramente el exceso de temperatura en la superficie interna, adquiriendo ciertas características grisáceas con tonalidades claras.

La cerámica del estilo Soras o Chicha Tardío presenta una pasta de textura porosa, compacta, compuesta por granos toscos, el color de la pasta es naranja y gris con la manufactura modelada, la superficie interna presenta engobe de color amarillo y marrón con un agregado de pintura diluida de color marrón aplicado mediante la técnica del brochado, además la superficie externa es áspera y de color negro o gris. Predominan las formas de cántaros con cara gollete y cuello recto y con los bordes 


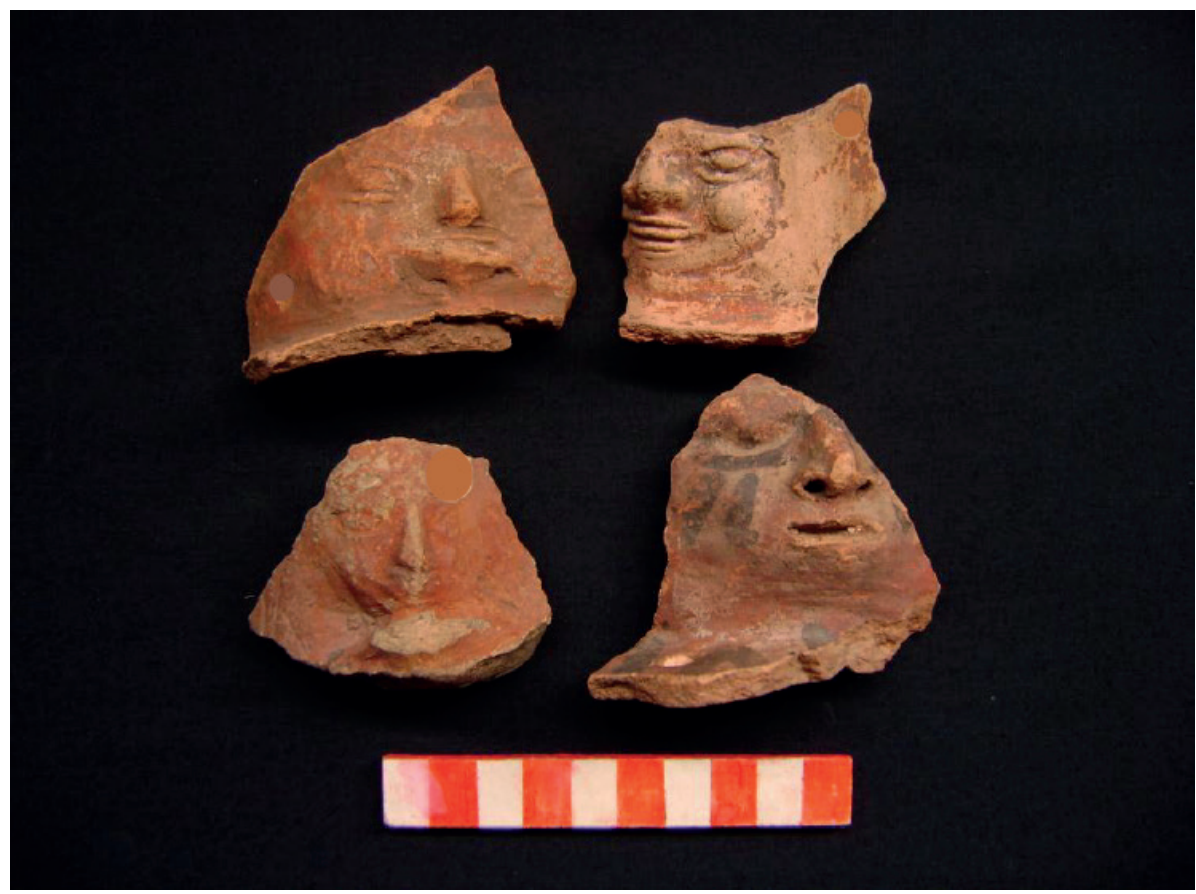

Figura № 23. Fragmentos de cerámica del estilo Chicha identificados en

Chiqnajota.

(Foto: Rafael Mallco, 2009).

expandidos. Las aplicaciones faciales están hechas por segregaciones de delgadas capas de arcilla adquiriendo una apariencia incisa.

La base de los cántaros es de forma cónica o mamiforme, los cántaros poseen asas cintadas en forma vertical y se encuentra sobre el diámetro máximo del cuerpo.

No se han identificado formas de platos, vasos ni cuencos, por el cual su forma nos indica de haber sido usados como vasijas para almacenar granos u otro tipo de productos.

La mayor cantidad de fragmentos poseen un engobe de color guinda y cochinilla que es poco diferenciable en la superficie exterior

Otra de las características típicas de los sitios tardíos en el valle Chicha es que las cuevas, los pedregales, las concavidades rocosas han sido utilizadas como lugares de enterramiento, posiblemente destinados para la gente común y corriente. En cambio para los personajes de importancia construyeron chullpas de formas circulares cerca de los poblados (Ver Figura. № 27 y 28).

Después del ocaso Huari la práctica de enterrar en cámaras funerarias, mausoleos, construcciones circulares subterráneas fue dejado para dar paso a una simple utilización de las cuevas como lugares de entierro, es por ello que las concavidades y abrigos rocosos de formación natural han sido utilizados como lugares de entierro durante el Intermedio tardío. Las cuevas habrían sido de manera sistemática acondicionadas para depositar los cuerpos con sus respectivas ofrendas, por ello, delimitaron 
con delgados muros adosados a la formación rocosa, estos presentan su respectivo acceso. A medida que fueron usando, las cuevas han sido remodeladas para darle un uso adecuado. Las cuevas y abrigos rocosos de Kallpa, Pachachaka, Turkuymalla y Marcalo, constituyeron lugares que eran utilizados con fines de enterramiento, las evidencias de restos de muros identificados en la superficie nos indican que la parte externa o entrada era cerrada mediante un muro de protección, de esa manera se aislaba la parte interna donde se depositaba el cadáver con sus respectivas parafernalias enterrado bajo el nivel del piso ya sea en tubas individuales o colectivas. También existen osarios constituidos por cavidades exprofesamente elaboradas, como en los pedregales de Pachachaka, donde se identificaron cuerpos pertenecientes a posibles guerreros depositados bajo grandes bloques de piedra, acumulados y rellenados por piedrecillas de diferente tamaño.
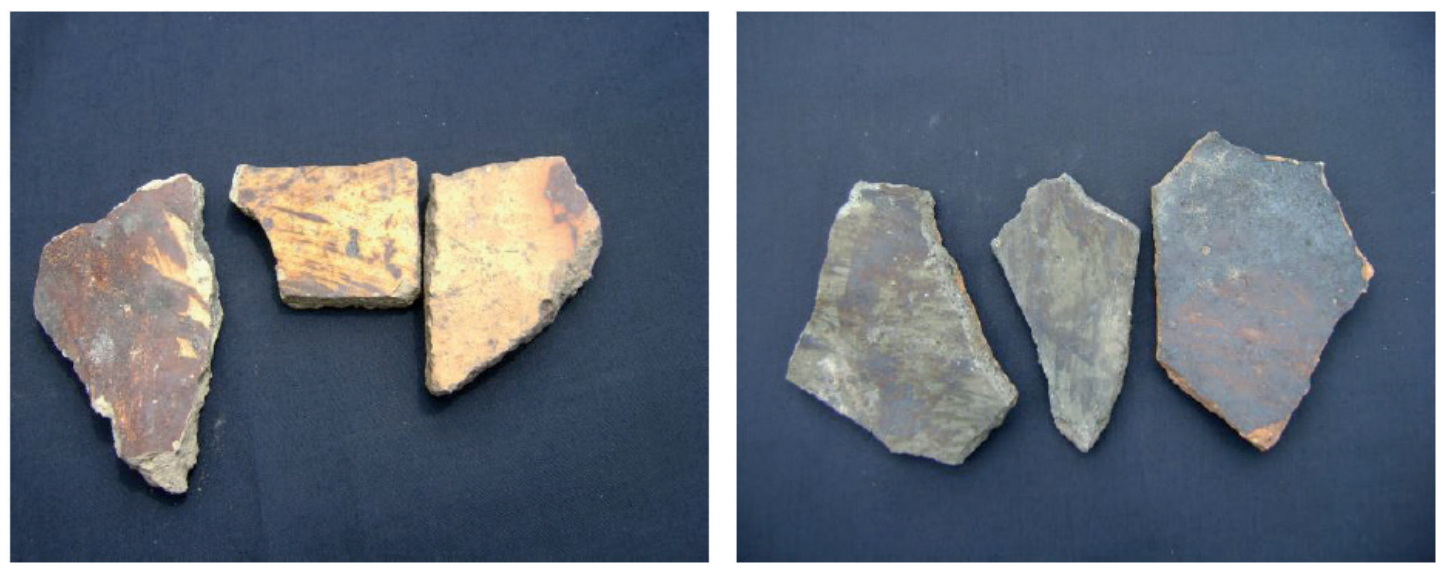

Figura $N^{\circ} 24$ y 25. Izquierda: Fragmentos de cerámica del estilo Soras cocidas a temperatura normal. Derecha: Fragmentos de cerámica del estilo Soras cocida a más de $1000^{\circ} \mathrm{C}$. Ambos proceden del declive Oeste de Obrajería. (Fotos: Rafael Mallco, 2009).

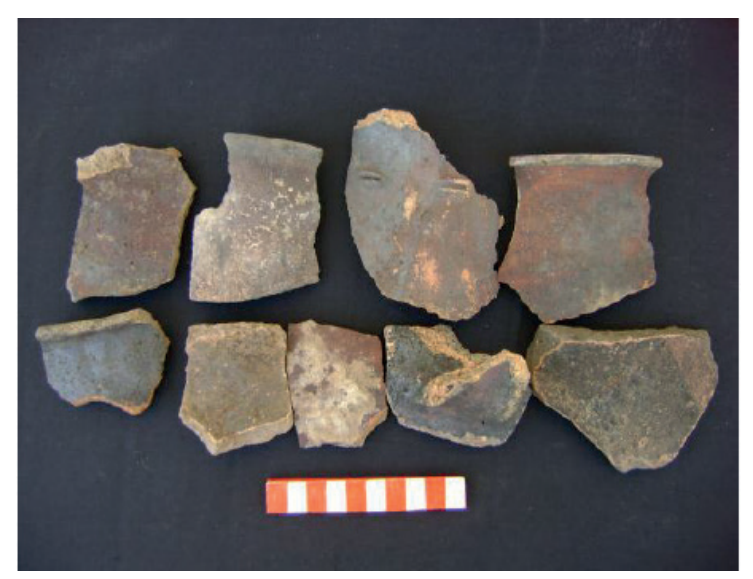

Figura $N^{\circ} 26$. Fragmentos de cerámica del estilo Soras procedente de Chiqnajota. (Foto: Rafael Mallco, 2009). 


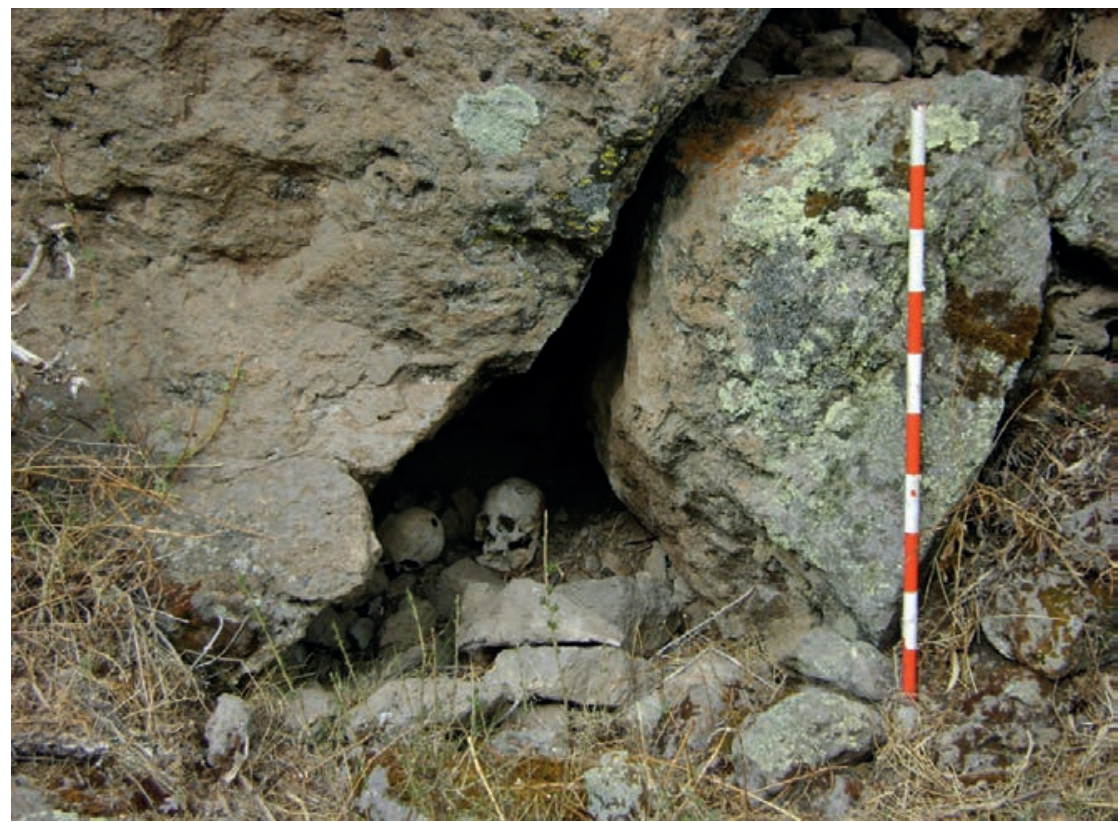

Figura № 27. Ubicación de una tumba debajo de un bloque de piedra en Pachachaka. (Foto: Rafael Mallco, 2009).

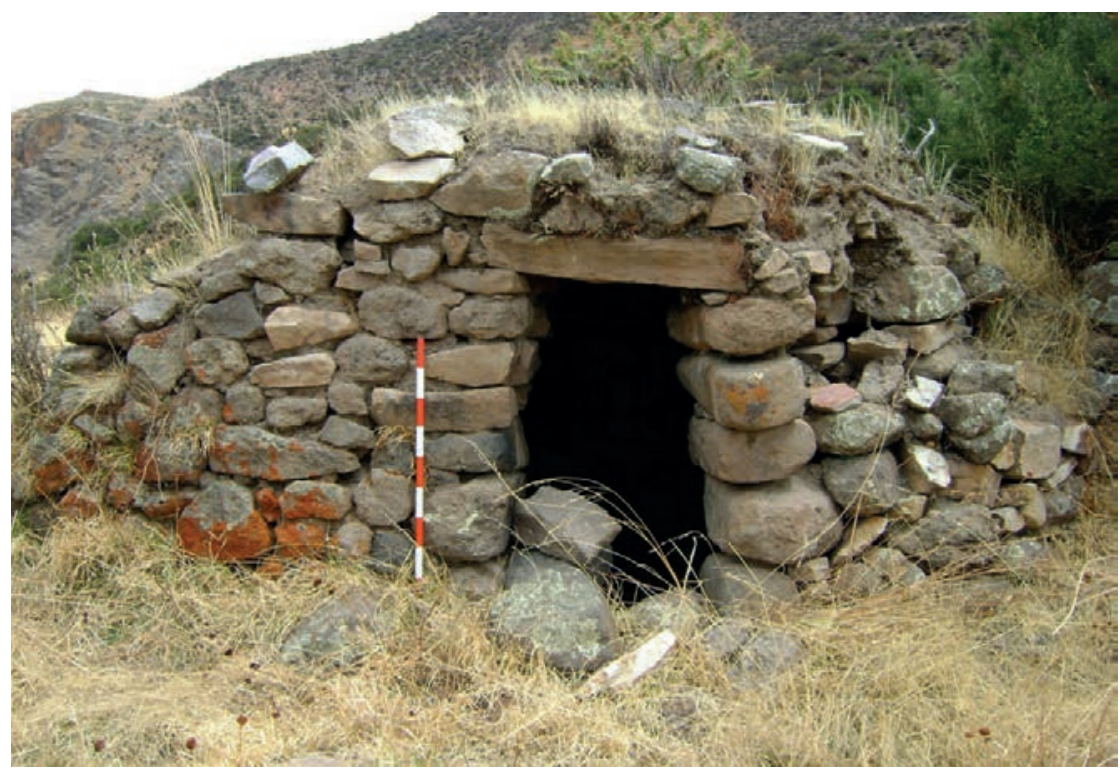

Figura № 28. Chullpa del Intermedio Tardío en el sitio arqueológico de Pulluhuay.

(Foto: Rafael Mallco, 2009). 